\title{
Ascend of the herbivores, decline of the carnivores? The social stratification of food consumption profiles in Italy, 1997-2016
}

\author{
Filippo Oncini* ${ }^{*}$ Moris Triventi ${ }^{\dagger}$
}

September 2019. Unrefereed manuscript, pre-print.

\begin{abstract}
Using data from the Multiporpose Survey of Daily Life by ISTAT, this paper analyses the profiling and social stratification of food consumption among Italian adults from 1997 to 2016. We first apply Latent Class Analysis on a set of central food categories of the Mediterranean diet to document the existence of six consumption clusters, (herbivore, carnivore, hedonist, enhanced Mediterranean, paucivore, omnivore) and their relative size over time. Second, we employ fractional response models to illustrate how gender and education are associated with each of the identified clusters. Finally, we use variance-weighted least square regressions to document the evolution of gender and education gradients over time.

Results point to an increase in the relative size of the herbivores and omnivores, a substantial stability of the hedonists and paucivores, and a decline of the carnivores and enhanced Mediterraneans. Moreover, our findings highlight a substantial social stratification of food profiles and show that, within a broad picture of persistence, gender and education became more important in affecting the propensity of adopting certain profiles. Women and upper educated individuals are more likely to belong to clusters characterised by daily fruit and vegetable consumption. Moreover, women are also less likely to belong to clusters defined by the presence of alcoholics and soft drinks. In addition, the gap between upper and lower educated individuals in the probability of belonging to the omnivore profile, and the gap between women and men in the probability of belonging to the herbivore and hedonist profiles have increased over time.
\end{abstract}

\footnotetext{
* filippo.oncini@ unitn.it University of Trento

$\dagger$ moris.triventi@unitn.it University of Trento
} 


\section{Introduction}

Sociological works on eating display considerable diversity, as the social appetite spurs as many research questions as are the possible combinations of theoretical and methodological ingredients. Depending on our conceptual lenses, meals can be studied for their power to congregate and assimilate, as much as for their capacity to divide and separate. Aided by the growth of surveys on individuals' eating habits, quantitative research on the social stratification of food preferences has considerably increased over the past years. However, given the paucity of repeated cross-sectional datasets, only a few studies have systematically examined the evolution and patterning of food preferences over time.

In this light, this paper analyses the profiling and social stratification of food consumption among Italian adults from 1997 to 2016. By focusing on a set of central foodstuffs of the Mediterranean diet, this study is among the first to consider the social patterning and evolution of eating trends over a period of 20 years using a large representative sample of the Italian population. The overall aim is to throw light on the unfolding and persistence of food preferences, while paying attention to the diverse configurations of eating profiles. In other words, we do not concentrate on shifts in the consumption of single food items or culinary practices, but rather on the evolution of dietary regimes, namely combinations of edibles which can be more frequently found in the population. Despite this strategy does not allow to examine some of the recent specific food changes, such as the diffusion of ethnic proposals, the increasing appeal of organic products, or the growth in purchase of local and exotic foods, it has the advantage to bring to light some structural features regarding the trajectories and social patterning of eating. Ultimately, you may be sitting in a restaurant waiting for a fresh composition made with feijoa and guava while savouring Kobe meat with a side of organic okra, and yet all you would have ordered is an expensive cut of bovine meat with a vegetable side-dish and some fruit dessert as a closing.

In so doing, the paper builds on and bridges some complementary streams of the sociological literature that have focused on the cultural stratification of taste and on the links between food choices and health. In line with the bulk of empirical literature that identified cultural consumption profiles by discerning groups of individuals based on their similar tastes’ portfolio (e.g. Katz-Gerro and Jæger 2013), we make use of Latent Class Analysis (LCA) to single out different dietary profiles and how they have changed in prevalence over time. By examining staple foodstuffs, we do not give prominence, as already done by many, to the way preferences for cosmopolitan meals, broad gastronomic horizons or sustainability ethos signal symbolic boundaries and social class distinctions (Currid-Halkett 2017; Johnston and Baumann 2014; Oncini 2019). Rather, as aforementioned, we 
look at central nutritional categories that somewhat paradoxically have been neglected in favour of their culinary or symbolic manifestations. Finally, our expectations regarding the social stratification of dietary profiles and their evolution are rooted in the sociological literature on the influence of gender role models and cultural resources in explaining the adherence to healthier dietary conducts (Abel 2008; Connell 1995; Courtenay 2000).

The paper is structured as follows. After presenting the most relevant literature, we move on to outline some characteristics of the Italian context and some general expectations. Hence, we introduce the dataset, the variables of interest, and the analytical strategy employed to empirically identify food consumption profiles, and to investigate their social stratification by gender and education. We then proceed to present the main findings: we first pigeonhole the six food profiles by analysing their diverse composition, and then outline their evolution over time; second, we illustrate how gender and education are associated to each of the identified classes in the full sample; third, we present the evolution over time of these gradients. We conclude by discussing the main limitations and advantages of the methodology herein employed, and by suggesting some possible developments for the study of food consumption and eating practices.

\section{Food consumption: Evolutions and stratifications}

Sociological research has always paid attention to the evolution of food consumption trends and their social stratification. The practice of eating is however a multifaceted cultural complex which is suitable for many types of descriptions depending on the components elements we are focusing on. As suggested by Yates and Warde (2015), one may look at key ingredients - as we do, or at their combinations (i.e. dishes); at the sequence of courses, or at the patterns of eating events; at the way families obtain and prepare food, or at the social organisation of eating occasions. And yet research interests must face the paucity and scattering of the available data, especially when a long-term perspective is adopted. For this reason, apart from well-known socio-historical accounts on changes in table manners, food preferences and culinary practices (Dickie 2008; Elias 2000; Mennel 1985), few studies provide systematic evidence on changes over time in the practice of eating.

To date, repeated cross-sectional studies conducted on population-based samples in Great Britain (Cheng et al. 2007; Yates and Warde 2015), Nordic Countries (Gronow and Holm 2019), Belgium (Mestdag and Glorieux 2009), France and USA (Plessz and Étilé 2019), and the Netherlands (Mandemakers and Roeters 2015) have mainly concentrated on modifications in commensality patterns, time devoted to cooking, and eating occasions to detect the signs of diminishing meal sociality, increasing commodification of the food chain, diffusion of eating and drinking out, and partial informalization of eating etiquette. In a few cases attention is given to the way social divisions 
in food consumption have been restructured: for instance, Cheng et al. (2007) show that the time (and resources) devoted to eating out by higher educated individuals in the UK may have become a possible mark of social distinction. Differently, Purhonen and Gronow (2014) compare Finnish culinary tastes between 1995 and 2007 and find a substantial stability of the opposition between light/ethnic and heavy/meat eating patterns, though the gender gap among tertiary educated individuals seem to have faded away. Yet, although most of these studies can cover many tens of years, they seldom have detailed information on the actual food consumed and how it is differently stratified. Rather, this aspect has mostly been scrutinised through various lenses but always looking at patterns of food preferences at one point in time (e.g. Darmon and Drewnowski 2008; Flemmen, Hjellbrekke, and Jarness 2018; Plessz and Gojard 2015; Warde et al. 2019; Oncini and Guetto 2018)

Starting with Bourdieu's (1984) influential argument on a correspondence between social position and taste, part of the debate on food stratification has in fact followed the conceptual coordinates deployed in the wider cultural stratification debate. Since Peterson's (1992) work on the seemingly decline in the United States of the homology between upper classes and high-brow culture engagement, empirical research has dedicated attention to the spread of the cultural omnivore, a taste profile characterised by the simultaneous presence of low- and high-brow tastes, possibly evidence of a greater tolerance in the realm of consumption or conversely a new way of expressing distinction through the ostentation of open-mindedness and eclecticism (Pedersen, Jarness, and Flemmen 2018; Warde, Wright, and Gayo-Cal 2007; Warde 2011). Research in various countries has produced fairly consistent results regarding the existence of the cultural omnivore as opposed to the univore or paucivore, and highlighted the presence of a group of upper status individuals that fit the metaphor in the fields of arts participation, musical tastes, attendance to cultural events and books preferences (Alderson, Junisbai, and Heacock 2007; Chan and Goldthorpe 2007a, 2007b; Fishman and Lizardo 2013; Garcia-Alvarez, Katz-Gerro, and López-Sintas 2007; López-Sintas and Katz-Gerro 2005; Zavisca 2005).

These new omnivore tendencies of the upper classes have then been disclosed in the food realm as well (Flemmen, Hjellbrekke, and Jarness 2018) and many studies unveiled the disparate, and at times contradictory, ways food and culinary practices can be used as markers of distinction. Upper status individuals can draw symbolic boundaries through exoticism and authenticity, but also by provisioning food through ethical channels or by 'invoking simplicity' (Currid-Halkett 2017; Johnston and Baumann 2014; Paddock 2015, 2016; Oncini 2019). Rather than a fixed set of manifold features, the reinvention of distinction is produced by the ability to select and combine information on production processes, new recipes, and culinary traditions, partly thanks to the increasingly 
heterogeneous offer that can be retrieved in the food market. For this reason, omnivores can mix eclectic gastronomic dispositions and concerns towards the environment, or simply prioritize some elements among the two (Huddart Kennedy, Baumann, and Johnston 2018). Yet lacking from this picture is the what behind the how: in other words, once agreed that pork stew and dumplings, or roast and adobo chicken, differ in form but not in content, we can start examining a different aspect of the social stratification of eating: are consumption differences socially patterned also when we consider staples instead of cuisines?

In part, this question is not entirely anew: the evidence on the impact of nutritional choices on individuals' wellbeing (Willet et al. 2019), has in fact channeled sociological literature towards an examination of social divides in healthy eating patterns. For if medical literature called attention to the higher propensity of women and upper-class individuals to eat more in line with dietary advice (Darmon and Drewnowski 2008; Wardle et al. 2004), two main sociological insights have been proposed to throw light on such patterns. On the one hand, it has been underlined how masculinity is often associated to invulnerability, competitiveness, downplay of safety and denial of health-concerns (Connell 1995; Courtenay 2000), which in turn can distance men from more salubrious choices, such as moderating the intake of red and cured meat, eating more fruit and vegetables and avoiding alcohol abuse (Rothgerber 2013; Van Gundy et al. 2004; Oncini and Guetto 2018). On the other hand, healthier dietary patterns among upper status individuals can be explained by looking at the role and function of material and immaterial resources. Abel's (2008) application of Bourdieu's (2011) theory of capitals on health studies suggests how different types of resources can affect food choices: cultural capital may influence food literacy and the incorporation of health related-values; economic capital can ease the access to wholesome meals; social capital can instead prevent household food insecurity and experiences of hunger (Martin et al. 2004). Notwithstanding, most quantitative research in health sociology and food consumption usually concentrates on single food items or indices of dietary compliance (e.g. Skafida 2013; Oncini and Guetto 2017) and rarely considers how foods or eating practices are clustered together (but see de Morais Sato et al. 2016; Flemmen, Hjellbrekke, and Jarness 2018).

\section{Context of the study and expectations}

The Italian case is particularly well suited for analysing food consumption patterns. Besides the unique opportunity to work on a dataset covering 20 years of consumption patterns, the country presents a set of features that makes the systematic analysis of food stratification worthwhile. Apart from the centrality of food for Italian cultural life and the relatively recent reinvention of local and regional gastronomic traditions (DeSoucey 2010; Lelieveldt 2017; Leitch 2003), the country is 
famous for the diffusion of foodstuffs that constitute the core of the Mediterranean diet, widely known for its health promoting qualities and affordability (Drewnowski and Eichelsdoerfer 2009; FerroLuzzi and Branca 1995). At the same time, studies have noticed that over the past decades people have been moving away from the Mediterranean model (Dernini and Berri 2015), probably following the increase of more diverse and commodified food supply. Moreover, as in many other industrialised countries, Italy has assisted to the rise of new dietary trends. In particular, in light of the increasing evidence regarding the impact of meat consumption on both the environment and on personal health (Oleschuk, Johnston, and Baumann 2019), vegetarian and vegan diets have become more widespread and are now respectively endorsed by $5.4 \%$ and $1.9 \%$ of the adult population (18+) (Eurispes 2019). For this reason, we might expect to capture an increasing prevalence of diets rich in fruit and vegetables and a decline of meat-based diets.

On the sociodemographic side, two main factors should be kept in mind. On the one hand, in the last decades there has been an increase in egalitarian attitudes toward gender roles, which could have weakened the ways certain dietary patterns are perceived as more masculine or feminine. At the same time however, the country is still characterised by traditional gender role models (Esping-Andersen 2009; Lomazzi 2017) which in turn may create marked cleavages in the food choices of men and women (Connell 1995; Courtenay 2000). For this twofold reason, we surmise that women are more likely to belong to healthier dietary patterns, whilst men to less salubrious ones, although this gap could have become less strong over time. On the other hand, following Abel (2008) we expect to find an educational gradient in the probability to belong to healthier and unhealthier dietary profiles. Nonetheless, the increasing heterogeneity in the food supply that partially replaced the 'healthy-bydefault' Mediterranean style, might have made more difficult to find and correctly interpret information on healthy and unhealthy dietary choices, potentially enhancing the gap between lower and upper educated individuals over time.

\section{Data and Variables}

We use data from the Multipurpose Survey of Daily Life by ISTAT (Italian National Statistical Institute) from 1997 to 2016. Cross-sectional surveys with a randomly selected, nationally representative sample of Italian families have been carried out each year but in 1996 and 2004. The analytical sample consists of adults in working age between 25 and $64 .{ }^{1}$ We ended up with a sample size amounting approximately to half million cases $(\mathrm{N}=481,359)$ with non-missing values for all the variables considered $(91.3 \%$ of the analytical pooled sample, with a percentage of missing ranging from $7.3 \%$ to $10.7 \%$ depending on the wave). Sample sizes for each wave are reported in Table A1 in the supplemental material. 
The survey collects information on the dietary habits of the respondents. We selected eleven food items available in all waves that offer an adequate representation of the central nutritional categories in Italians' diets. These are: pork, bovine, cured, and white meat, fish, vegetables in leaf, vegetables in fruit, fruit, soft-drinks, beer, and wine. ${ }^{2}$ The questionnaire asks the frequency of consumption for each food item. Possible response categories are: more than once per day, once per day, sometimes per week, less than once per week, never. We recoded the food variables in dummies distinguishing between edibles consumed at least once per week (1) or less $(0) .{ }^{3}$ Only in the case of the two vegetable types and fruit, given the response distribution, we separate between every day (1) or less (0). In the case of soft drinks, wine and beer, possible response categories are: more than 1 litre per day, from half to 1 litre per day, 1-2 glasses per day, more rarely, only seasonally, never. Also in this case, we recoded the variables in dummies distinguishing between drinks which are part of the dietary habits (1) or which are only consumed seasonally or never (0). Explanatory variables include gender, educational level (primary or less, lower secondary, upper secondary, tertiary), macro-area of residence (north, centre, south or islands), marital status (single, married, separated/divorced, widowed) and age. ${ }^{4}$

\section{Analytical Strategy}

The analysis is organized in three main stages. First, we identify the main food consumption profiles in Italy and describe their characteristics. Second, we examine whether the adoption of specific food consumption patterns is socially stratified by gender and education. Third, we investigate whether the social stratification of food consumption profiles has changed over time.

First, to identify the food consumption profiles, we applied latent class analysis (LCA, hereafter) (Vermunt and Magidson 2004) on the pooled sample using the 11 binary items previously described. ${ }^{5}$ LCA can be considered a categorical data analogue of factor analysis which allows the researcher to empirically identify discrete latent classes from a number of discrete observed variables (McCutcheon 1987). LCA aims at identifying a set of classes of a latent variable within which the observed indicators (our 11 binary items) are locally independent. Following standard practices in cultural stratification research, we think of the latent classes as capturing subgroups of respondents with similar dietary patterns. The LCA model can be written as such (Jaeger and Katz-Gerro, 2013: 249)

$$
P\left(u_{j}\right)=\frac{\exp \left(\lambda_{1 j} * 1(K=1)+\lambda_{2 j} * 1(K=2) \ldots+\lambda_{k j} * 1(K=k)\right.}{1+\exp \left(\lambda_{1 j} * 1(K=1)+\lambda_{2 j} * 1(K=2) \ldots+\lambda_{k j} * 1(K=k)\right.}
$$

where $\lambda$ is the conditional probability of having in the diet the food item $j$ given class membership $k$. To fit a latent class model, we must specify the number of classes in the latent variable. In order to select the optimal number of profiles, we gradually increased the number of latent classes $K$ (from 2 
to 8) and relied on both theoretical interpretation of the results and model fit statistics such as the Loglikelihood, Bayesian and Akaike Information Criteria and entropy (see Table A3 in the supplemental material). ${ }^{6}$ Our preferred solution consists of 6 classes, which is a reasonable compromise between detail and parsimony in our context. We used the probabilities of class membership to measure the latent class sizes, which provide an indication of the share of individuals in each latent group. We used the conditional probabilities for the food items within each latent class to identify the characteristics of the latent groups and assign them meaningful labels to ease the interpretation of the research findings.

In the second stage, we analysed individuals' class posterior probabilities of belonging to each of the six latent classes identified by LCA as dependent variables in a series of fractional response models, which use a logit model for the conditional mean of the outcome (Papke and Wooldridge 1996). ${ }^{7}$ Since individuals' probabilities to belong to each class varies between 0 and 1 , fractional logistic regression (FLR) enables to account for the boundedness of the dependent variable, and it is especially useful when response variables exhibit positive probability mass at one or both corners (Buis forthcoming). For consistent parameter estimates, FLR does not assume any distribution of the dependent variable, but only requires the conditional mean to be correctly specified (Wooldridge 2010). Our estimates are unbiased under the (weak) assumption that the logistic function is appropriate for modelling the likelihood of belonging to the six latent classes identified in the first step. In this second stage, we estimated six models on the pooled sample to assess to what extent, overall, gender and educational level were associated to the probability of adopting each food consumption profile, controlling for year of the survey and the other control variables described before.

In the third stage, we aim to assess whether the effect of gender and education on the probability of belonging to each of the six food consumption profiles changed over time. To answer this question, we adopted a two-step strategy. First, we estimated FLR for each outcome with a model specification analogous to the one just described, but separately for each year. Then, we computed the average partial effects (APEs) (and their corresponding standard errors) of the gender and education variables, to quantify their association with the probability of adopting the six dietary patterns across years. While in the case of gender there is only one APE of interest, in the case of education there are three APEs, since this variable has four categories. To provide a unique measure of the association between education and each dietary pattern, we computed what we called the mean APE ( $m$ APE), in this way:

$$
m A P E=\left(A P E_{2-1}+A P E_{3-1}+A P E_{4-1}\right) / 3
$$


which can be interpreted as the average difference between the individuals with medium-lower educational level (primary, lower secondary and upper secondary) and those with tertiary education in the probability of belonging to each food consumption profile. Standard errors around this measure were computed using the delta method (Oehlert 1992).

In a second step, we used such APEs as dependent variables in variance-weighted least square (VWLS) regressions (Strutz 2016) in which the independent variable is year entered as a continuous variable. In these models, the coefficients associated with the year variable provide a measure of the degree of (linear) change over time in the effect of gender and education, and the p-values provide information on its statistical significance. VWLS is equivalent to linear regression but it does not assume homogeneity of variance, since it reweights the estimates on the basis of the standard errors of the outcome variable (which we computed in the first step along the point estimates of the APEs). Our analytical strategy is computationally less cumbersome than a one-step pooled model with interaction terms between the social stratification variables and year, and - at the same time - does not constrain the effect of the control variables to be the same across all years, providing a greater flexibility in the model specification (Heisig, Schaeffer, and Giesecke 2017). To check whether the linear trend fitted by our models is a good approximation of the observed APEs over years, we compared our results with those from locally weighted regression (Cleveland 1979), a flexible technique to model change over time without imposing strong parametric assumptions to the data.

\section{Findings}

\section{Food consumption profiles and their trends over time}

We begin our analysis by showing the results from the Latent Class model with six classes estimated on the pooled sample. Figure 1 uses radarplots to illustrate the probability of endorsing the eleven food items conditional on belonging to each of the six dietary profiles, whereas Table 1 presents the estimated size of each cluster as a percentage of the total sample.

\section{FIGURE 1 HERE}

The first food profile is labelled carnivore as respondents who tend to belong to this food profile have a high probability (>0.6) of consuming all types of meats (especially chicken and beef, higher than $0.9)$ and fish, while presenting low probabilities for all the other edibles and drinks. The second cluster, named herbivore, contains respondents exhibiting a very high probability (>.8) of consuming daily fruit and both types of vegetables, while tending to exclude all the other food items from their weekly diet. The hedonist profile compared to the other ones is the unhealthiest cluster. This profile gathers together individuals that tend to avoid vegetables and fruits, while having higher probabilities 
of consuming all types of animal products (>.6), beer, wine and soft drinks (>.7). The enhanced Mediterranean group could be seen as the most traditional cluster, as it is characterised by the simultaneous presence of meats (especially chicken and beef), fish, and the high probability of consuming daily fruit and vegetables (>.7), but low probability of endorsing wine, soft drinks and particularly beer. Finally, we label paucivore and omnivore the fifth and sixth profile, as they capture respondents who respectively exhibit polarised probabilities of consuming all the 11 items considered in this study. In other words, the former group is characterised by a limited consumption of widely diffused staples, whilst the latter presents the most heterogeneous consumption profile, with all edibles and drinks having medium to very high probabilities of being part of respondents' diets. These two profiles resonate with the literature on cultural stratification documenting the existence of an opposition between a group characterised by low attendance to common cultural activities (so called paucivore, univore or limited) and another one, more eclectic, that has high probability of enjoying both highbrow and popular activities (e.g. Alderson, Junisbai, and Heacock 2007; Chan and Goldthorpe, 2007a, 2007b; Jaeger and Katz-Gerro 2013).

Looking at the estimated sizes of the different profiles (Table 1), the largest group is constituted by the enhanced Mediterranean, amounting to almost $24 \%$ of the sample. This cluster outdistances by around 10 percentage points the hedonist (13.8\%) and the herbivore groups (14.3\%). The remaining three clusters are instead slightly larger: paucivores make up $15.2 \%$ of the sample, omnivores $16.2 \%$ and carnivores, the second largest, $16.8 \%$.

\section{TABLE 1 HERE}

Hence, Figure 2 illustrates the estimates of the relative sizes of the six food profiles from 1997 to 2016 obtained from the Latent Class model applied on the pooled sample. Three considerations are in order: first, in line with our expectations, there is an increase in the magnitude of the herbivore cluster, that moves from $14.6 \%$ in 1997 to $19,1 \%$ in 2016, and a reduction in the sizes of the carnivore and the enhanced Mediterranean profiles. The former has an opposite trajectory compared to the herbivore, going from $18.0 \%$ in 1997 to $13.3 \%$ in 2016, whereas the enhanced Mediterranean drops from $25.3 \%$ to $19.4 \%$, thus becoming almost equal in size to the herbivore cluster. Second, the omnivore cluster grows from $13.8 \%$ to $17.5 \%$ : this trend probably captures an increasing proportion of individuals who are more open regarding the available food options, and that take advantage of the proliferation of a heterogenous food supply. Finally, the hedonist and the paucivore clusters, despite some minor fluctuations, remain rather stable nearing $14.0 \%$ and $17.0 \%$ in 2016 .

\section{FIGURE 2 HERE}


The social stratification of food consumption profiles

Moving to the social stratification of the dietary profiles, Figure 3 illustrates the average partial effects of gender and education on the probability of belonging to the 6 dietary profiles, derived from fractional logistic regressions. Gender differences are relevant in four profiles. Women are less likely to belong to the omnivore (-9 percentage points) and hedonist profiles (-12 percentage points), and more likely to belong to the herbivore ( +7 percentage points) and enhanced Mediterranean $(+12$ percentage points). The results mirror existing studies showing that women have healthier dietary conducts (Rothgerber 2013; Van Gundy et al. 2004), as they are more likely to belong to all clusters without beer, wine and soft-drinks but with high probability of presenting fruit and vegetables - with the exception of the carnivore profile.

\section{FIGURE 3 HERE}

As for socioeconomic divides, we find a monotonic association between educational level and profile membership for four food clusters: tertiary educated individuals are more likely to be part of the herbivore (+6 percentage points) and omnivore profiles ( +5 percentage points) compared to individuals with no more than primary education. At the same time, they are 6 and 4 percentage points less likely to belong to the carnivore and enhanced Mediterranean profiles. Also in this case, results are partially in line with studies on health and cultural stratification: upper status individuals are more likely to eat fruit and vegetables (Darmon and Drewnowski 2008), but also to have more omnivore taste profiles, also when we move from cultural participation and tastes to food preferences. At the same time however, no substantive association is found between education and the hedonist and paucivore profiles.

\section{Trends over time in social stratification of food consumption profiles}

Finally, in the last step of the analysis, we investigate whether the social stratification patterns we described in the previous section changed from 1997 to 2016. As described in the analytical design section, we have estimated separate fractional logistic regression models for each survey year. Figures 4 and 6 plot the predicted probabilities of adopting a given dietary style for women and men (Fig. 4) and the four educational groups (Fig. 6) derived from such models, which adjust the estimates for age, geographical area and marital status. These graphs allow us to observe whether the social categories of interest have been characterized by similar, convergent or divergent trends. Figure 5 and 7 serve as a complement, since they report the APEs and the corresponding confidence intervals for the gender and education variables respectively. In these figures, we also report the results of the variance weighted least square regression, which interpolates the APEs to test whether we can detect a statistically significant linear trend over time. Lowess smoothed estimates of the time trends are 
also reported to check whether the linear trend is a good approximation of the changes of interest. In general, the linear fit is a good approximation of trends over time, with only a few exceptions, which we will mention in the comments. Finally, Table 2 summarises the results obtained.

\section{FIGURE 4 and 5 HERE}

Looking at gender, Figure 4 and 5 show that the absence of gender differences in the probability of being paucivore has been constant over time, and the modest and continuous decline over time in the probability of being carnivore affected both men and women to a similar extent. Women have been always more likely to be herbivore than men and their propensity to adopt such dietary style increased to a larger extent, especially since 2010. Figure 5 indicates that the gap enlarged significantly by approximately 3 percentage points from 1997 to 2016, which correspond to a growth of more than $50 \%$ in relative terms. Women were also more likely to belong to the enhanced Mediterranean profile, but the declining trend in this food consumption class has affected both genders, even if slightly more women, especially from the mid-2000s. The last two profiles, hedonist and omnivore, have attracted disproportionally more men than women in the twenty years analysed in our study. In both cases the gender gap increased over time, by around 4 percentage points in the case of hedonists, and by 2 percentage points in the case of omnivores (see Figure 5). While women maintained their propensity of adopting a hedonist style fairly stable over time, the same propensity increased to a higher extent among men. Differently, the probability of being omnivore grew both among men and women, but to a higher degree among women, especially at the end of the 1990s (see Figure 4).

Considering the educational level, Figure 6 shows that lower educated individuals have been more likely to be carnivore and to adopt the enhanced Mediterranean style of food consumption from the mid-1990s to the mid-2010s, and the overall differences across the educational categories have been fairly constant over time (see Figure 7). A pattern of persistent differences is visible also in the case of the hedonist and herbivore profiles. On the one hand, the probability of being hedonist has been very similar across individuals with different educational levels for the whole period covered by our data. On the other hand, medium-lower educated individuals were less likely to be herbivores than tertiary educated individuals already in the mid-1990s; then, the differences across educational groups stayed stable around 5 percentage points, with only a slight enlargement since 2012 (see the lowess smoothed trend in Figure 7).

\section{FIGURE 6 and 7 HERE}

The only two food consumption profiles in which we were able to detect statistically significant changes in the educational stratification patterns are the paucivores and omnivores. Starting from the 
latter, lower-medium educated individuals were less likely to be omnivores already in the mid-1990s and then the gap with tertiary educated individuals increased by more than 3 percentage points in the whole period. This pattern was mainly driven by individuals with no more than compulsory schooling (primary and lower secondary education), whose propensity to be omnivore remained rather stable in contrast to that of tertiary educated individuals, who became progressively more likely to adopt an omnivore dietary style. The association between educational level and the probability of adopting a paucivore style changed sign over the twenty years, with primary educated individuals becoming more likely to adopt such dietary pattern, especially with peaks in 2013 and 2016. However, one must bear in mind that differences among educational categories are small and this dietary style does not contribute much to the social stratification of food consumption patterns in Italy.

\section{Discussion and concluding remarks}

Using a unique repeated cross-sectional dataset on the foods most widely consumed by Italians, this paper investigated how the eating patterns of the population have evolved over the past 20 years. Besides being one of the few studies looking systematically at long time trends on eating, the article aimed to bridge two sociological scholarships that have produced the most important insights on food stratification. Cultural sociology, and particularly the omnivore-univore debate, prepared the theoretical ground and the methodological toolkit for looking at food components elements and their assortment. Akin to many studies focussing on combinations of musical preferences or cultural activities, we examined through Latent Class Analysis how several core edibles are most commonly bundled together, hence producing different dietary profiles. Concurrently, insights from health sociology provided us with reasonable expectations regarding which food clusters could have come to light, and the directions of gender and education gradients.

Two main conclusions can be drawn from our analyses. First, despite huge changes in the food supply sector, the same combinations of staples tend to characterise food consumption patterns over the time span considered. This is a particularly engaging result, as in the same period the Italian food culture and its narration drastically evolved: new fast-foods chains entered the market and the Slow Food resistance emerged (Leitch 2003); the renewed attention towards local products created the conditions for the development of schemes for promoting and protecting quality agricultural products and preparations (DeSoucey 2010); haute cuisine conquered shows schedules while ethnic restaurants and products entered streets and markets (Caritas 2015; Pietro 2016). Possibly, this highlights the difference between the foods we eat and the way we eat them, the former characterised by a much more profound stability than the latter. 
At the same time, four clear trends in the size of these clusters are observed: the ascend of the herbivores and omnivores, and the descend of the carnivores and enhanced Mediterraneans. These results match the evidence coming from diverse studies on the increasing number of vegetarians and vegans (Eurispes 2019), on the rising awareness regarding meat consumption environmental impact ${ }^{8}$ (Oleschuk, Johnston, and Baumann 2019) and on the diminishing appeal of the Mediterranean diet (Dernini and Berri 2015). We surmise that similar patterns may have taken place also in Europe, and especially in southern European countries, given their similar food culture and economic trajectory.

Crucially, like other studies on taste profiles, we captured the presence of a group named paucivore, as well as the rise of the omnivore consumer (e.g. Chan and Goldthorpe 2007b; Jaeger and KatzGerro 2013). Yet two important caveats should be underlined. While it is not hard to imagine the existence of 'couch potatoes' disinterested in cultural events (Jaeger and Katz-Gerro 2013), it is definitely impossible to do without food. Consequently, it is plausible that the paucivore cluster captures either or both individuals with de facto narrow food preferences, or/and individuals with highly unconventional diets - what we may call "alternatives". Second, although omnivores are literally omnium voracious, it is hard to distinguish between popular and refined staples without additional information, though the simultaneous presence of soft-drinks and fish could point to that direction.

Second, results highlight a substantial social stratification of dietary profiles and show that, within a broad picture of persistence, gender and education became more important in affecting the propensity of adopting certain dietary profiles. In line with studies on health stratification, we find that women and upper educated individuals are generally more likely to belong to healthier profiles, i.e. characterised by daily fruit and vegetables consumption. Moreover, women are also less likely to belong to clusters defined by the presence of alcoholics and soft drinks. Interestingly indeed, the gap between upper and lower educated individuals in the probability of belonging to the omnivore profile has increased; similarly, women and men in 2016 differ more than in 1997 in the probability of belonging to the herbivore and hedonist profiles.

The lower probability of women to belong to the omnivore profile might be seen in contrast with some evidence on music, theatre and cinema attendance which suggests that they are more likely to have high-brow preferences and to be cultural omnivores (e.g. Chan and Goldthorpe 2005; Coulangeon and Lemel 2007; Purhonen and Gronow 2014). Yet all findings based on clustering techniques rely on the analytical selection (and availability) of the items, which inevitably foreclose the manifestation of alternative response patterns. This is especially true in the case of foods and drinks, as the enumeration of possible edibles is quasi-infinite, and profiles can be characterised so 
much from inclusion as from exclusion (Bryson 1996). Moreover, a recent study based on culinary dislikes in Finland highlight that women tend to have a higher range of aversions compare to men, namely, to be less omnivore (Lindblom and Mustonen 2019).

Two additional findings should be discussed: being the hedonist profile the unhealthiest of the six, one could have expected to find an education gradient; similarly, given the long-standing relation between masculinity and meat (Sobal 2006) one could have presumed the carnivore profile to be more populated by men. However, it should be noticed that this study is only capturing the probability of regular presence of the food items in the diet, and no conclusion can be drawn regarding the actual quantity eaten by respondents. ${ }^{9}$

Finally, we would like to address some limitations and future directions. First, latent class models applied on repeated cross-sections over time run the risk of underestimating qualitative shifts in the compositions of the clusters, while overestimating the change in the relative size of the groups. Yet this analytical strategy has the advantage of offering a more holistic view of eating changes over time, as it permits to observe how foods are most often combined.

Second, despite the edibles we have selected capture central nutritional categories of Italians' diets while responding to a need of parsimony, they are unavoidably inexhaustive of the complexity of the phenomenon. For instance, we do not have the same time series for important foodstuffs such as legumes, salty snacks, or nuts.

Third, we analyse whether groups of edibles are present or not in the weekly diet, but we are not observing the actual amount consumed by individuals, and most importantly their expenditure. Taken together, these three pieces of information - type of food, quantity, and expenditure - would lead to the construction of more sophisticated food profiles modelled around edibles presence or absence, number of portions, and quality. As an example, one could imagine distinguishing high- and low-end carnivores based on the quality of the meat cuts they consume. Future research would benefit from a more thorough data collection on food and cuisines, which could possibly link research from different sociological areas and far beyond. 


\section{Endnotes}

${ }^{1}$ Results do not change substantially if we run the same analysis on one family component randomly extracted from the analytical sample (see Table A2 in the supplemental material).

${ }^{2}$ Despite their centrality in the Mediterranean diet, we have excluded two variables gathering information on the consumption of i) bread, pasta, rice and ii) cheese. The former variable cannot be used because basically all the respondents declare to eat carbohydrates at least once per day. We have instead applied LCA adding cheese to the 11 items, and results remain substantially the same, although instead than one profile named Herbivore (see the results section) we end up with an additional (but smaller) herbivore profile that has a higher probability of endorsing the beer and wine items as well - what we may call a "hedonist herbivore". Nonetheless, since cheese has a high probability of endorsing all classes, its addition does not add much to the final picture. Results are available upon request.

${ }^{3}$ Following most of the contributions using latent class analysis, we decided to recode the variables on the frequency of consumption into dummies. There are three main reasons for this choice in our context: i) the distribution of most items is widely uneven across the original categories; ii) the categories used to measure the frequency of consumption are, to some extent, item-specific; iii) estimation of latent class model is much more computationally demanding on ordinal variables with characteristics such as the ones just mentioned.

${ }^{4}$ Due to a change in the way professional position is measured, we do not include social class as an explanatory variable, as this would imply the loss of 4 waves worth of data. Additional models applied on the years 2001-2016 are available in the supplemental material (Figure A1) and show that results do not substantially change when we include social class in the fractional logit models. Compared to education, social class is not substantially associated with any of the latent classes. This result is in line with what has been already found using the same data (see Oncini and Guetto 2017, 2018) and may suggest that in the Italian context cultural resources matter more than economic ones when it comes to food choices.

${ }^{5}$ The results do not change when the same model is estimated on each single year (see Table A5 in the supplemental material).

${ }^{6}$ To avoid local maxima solutions, we also estimated the same model on the statistical software Mplus using 100 sets of random starting values for the model parameters and 50 sets of random starts for the final-stage optimization. Even with very different sets of starting values our model consistently converges at the global maximum of the likelihood function.

${ }^{7}$ Most studies use "modal class assignment" to attribute individuals to the latent class with the highest class posterior probability to belong to (Vermunt and Magidson, 2004) and then use the generated categorical variable as outcome in a multinomial logistic regression to link the latent classes with a set of predictors. We believe this is an unnecessary step, and instead we opted for using directly the estimated class posterior probabilities as outcome variables in fractional logistic regression models, which are appropriate to model variables within the $0-1$ range, as in our case. Nonetheless, this choice does not alter substantially our findings since results obtained with the more traditional approach are consistent to the one presented in this article, as reported in Figure A2 in the supplemental material.

${ }^{8}$ Despite increasing health, environmental, and ethical concerns regarding meat, the overall consumption in many OECD countries remains rather stable (Kanerva 2013). This data should not be seen in contradiction with the decline of the carnivore profile, as in this paper we are not concerned with quantities, but just with the presence/absence of certain food items in the dietary cluster under observation. For instance, carnivores could have given way to omnivores without affecting the total amount of meat consumed.

${ }^{9}$ We have converted the original response categories of the five meat typologies and the two alcoholic drinks into portions per week in order to create two indices that roughly capture the total amount of meat and alcohol consumed. Figures A3 and A4 in the supplemental material illustrate that when we consider the overall consumption, the aforementioned associations still take place. Men eat on average more portions of meat than women, whereas the amount of beer and/or wine decreases the higher the educational level of the respondent. 


\section{Tables}

Table 1 - Posterior predicted probabilities of belonging to the six dietary profiles. Source: ISTAT-MDS 1997-2016.

\begin{tabular}{lrrccc}
\hline Variable & Observations & Mean & Std. Dev. & Min & Max \\
\hline Carnivore & 481,359 & 0.168 & 0.324 & 0.000 & 0.991 \\
Herbivore & 481,359 & 0.143 & 0.280 & 0.000 & 0.995 \\
Hedonist & 481,359 & 0.138 & 0.306 & 0.000 & 0.991 \\
Enhanced Mediterranean & 481,359 & 0.237 & 0.372 & 0.000 & 0.995 \\
Paucivore & 481,359 & 0.152 & 0.285 & 0.000 & 0.996 \\
Omnivore & 481,359 & 0.162 & 0.329 & 0.000 & 0.997 \\
\hline
\end{tabular}

Table 2 - Summary of results on the social stratification of food consumption profiles.

\begin{tabular}{lcccc}
\hline Variable & \multicolumn{2}{c}{ Gender (Female vs Male) } & \multicolumn{2}{c}{ Education (Low vs High) } \\
\hline Pattern & + & Trend & Pattern & Trend \\
\hline Carnivore & ++ & $\leftrightarrow$ & ++ & $\leftrightarrow$ \\
Herbivore & -- & $\uparrow$ & - & $\leftrightarrow$ \\
Hedonist & +++ & $\uparrow$ & 0 & $\leftrightarrow$ \\
E. Mediterranean & 0 & $\leftrightarrow$ & 0 & $\uparrow$ \\
Paucivore & -- & $\uparrow$ & -- & $\uparrow$ \\
Omnivore & $\uparrow$ & + \\
Note: + indicates females (vs males) and lower educated (vs highly educated) & are more likely to adopt a given dietary \\
style; the higher the number of symbols and the stronger is the relationship; $\uparrow$ indicates increasing social stratification, & \\
indicates stability of differences between social categories.
\end{tabular}




\section{Figures}
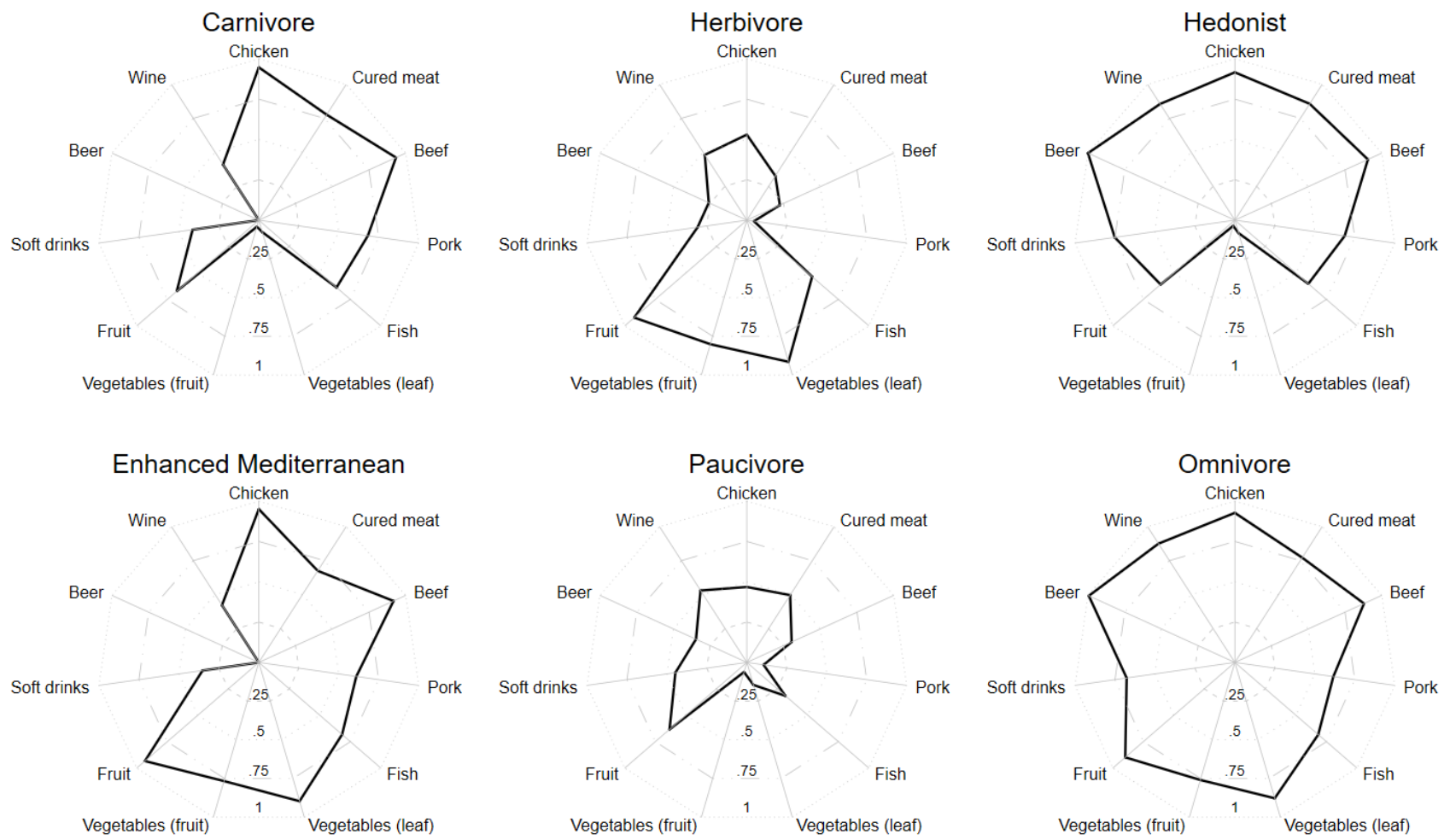

Figure 1 - Radarplot showing the profiles of the six classes: averages on the 11 items used in the latent class analysis. Source: ISTAT-MDS 1997-2016. See Table A4 for the details of the marginal predicted means. 

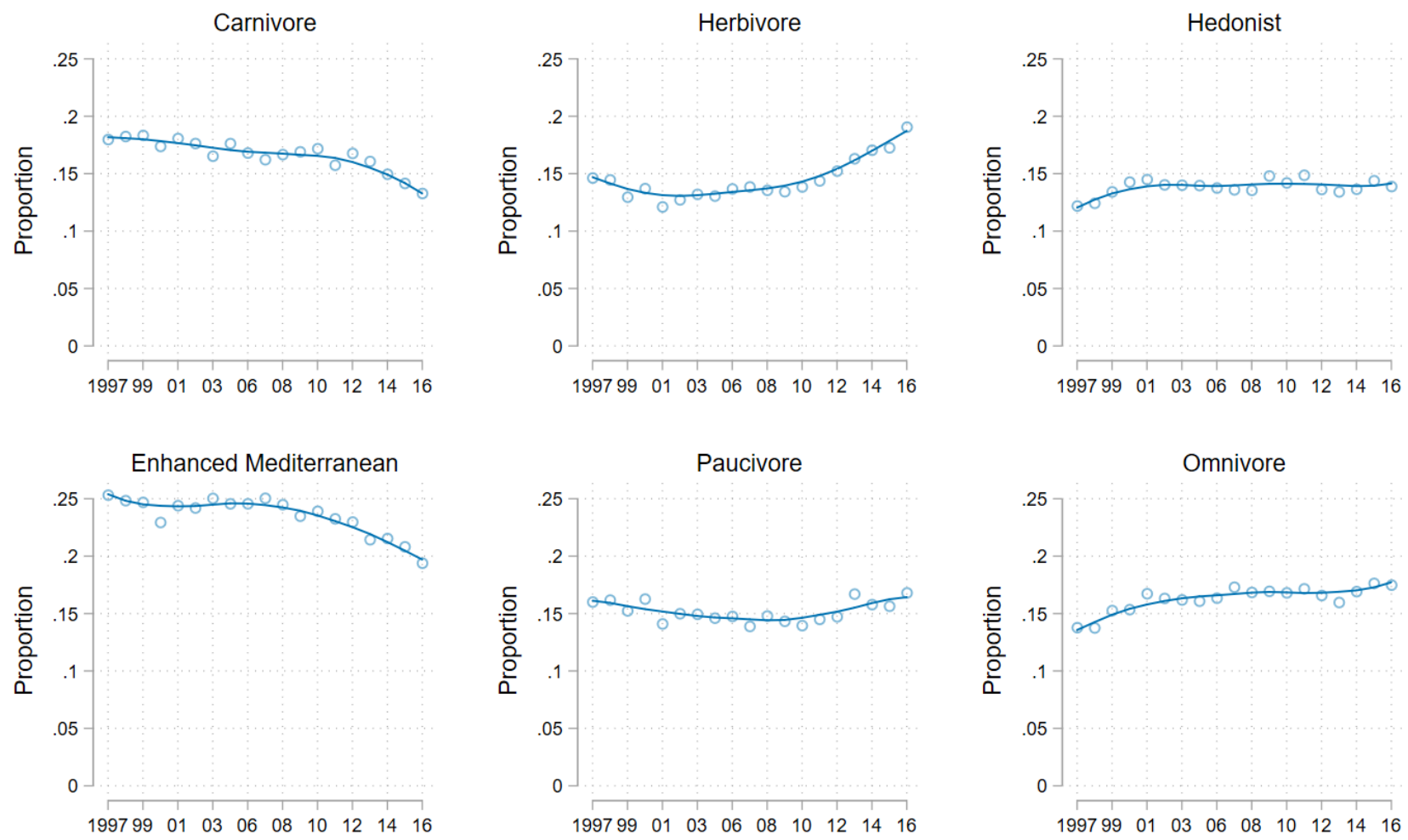

Figure 2 - Estimated incidence of the classes by year: marginal predicted probabilities for each latent class by year and smoothed trend over time with lowess smoothing (bandwidth=.6). Source: ISTAT-MDS 1997-2016. See Table A6 for the details of the predicted probabilities. 


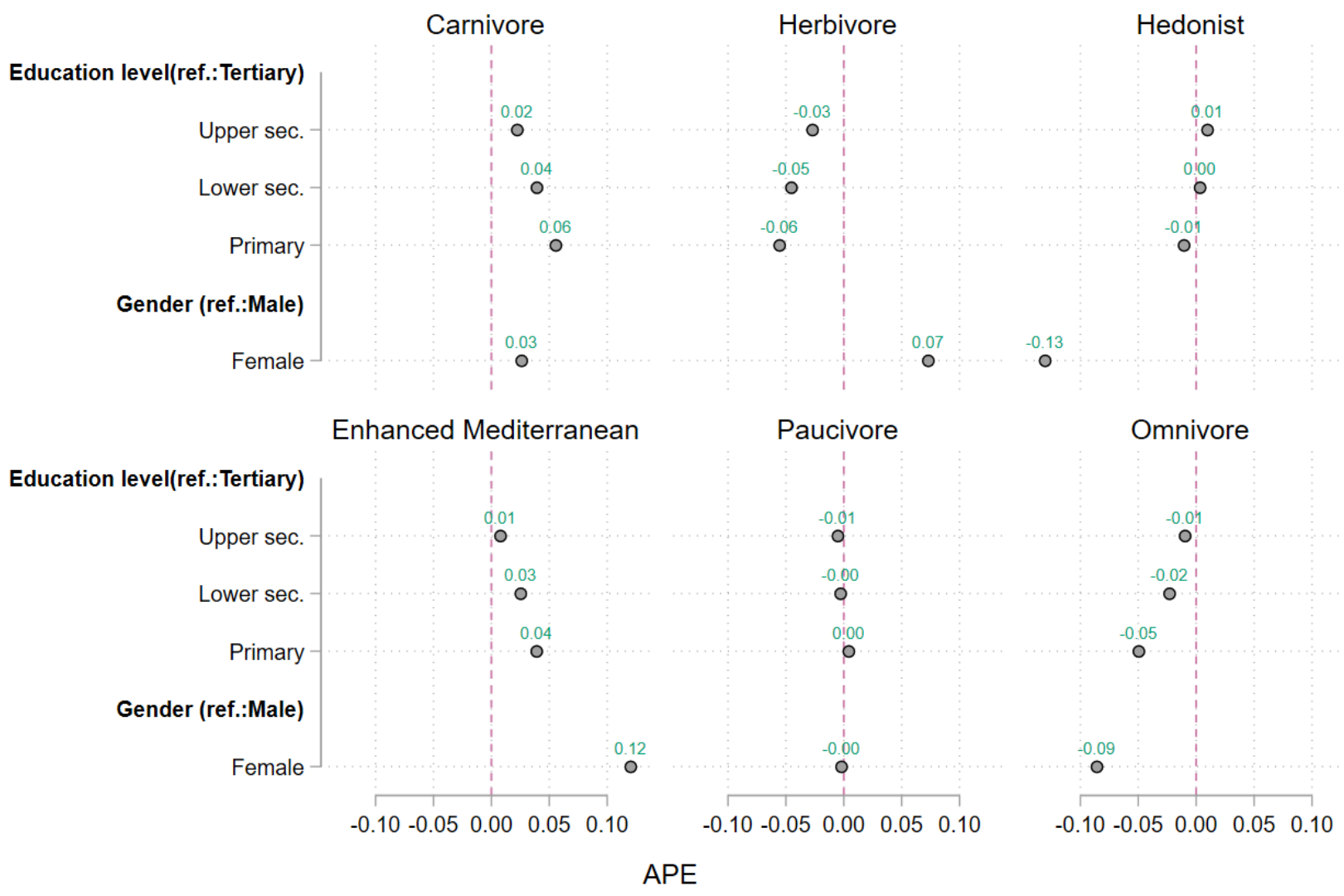

Figure 3 - Fractional logit models: average partial effects of education and gender on the probability of adopting different dietary styles. Source: ISTAT-MDS 1997-2016. Log odds are reported in Table A7 in the supplemental material. 


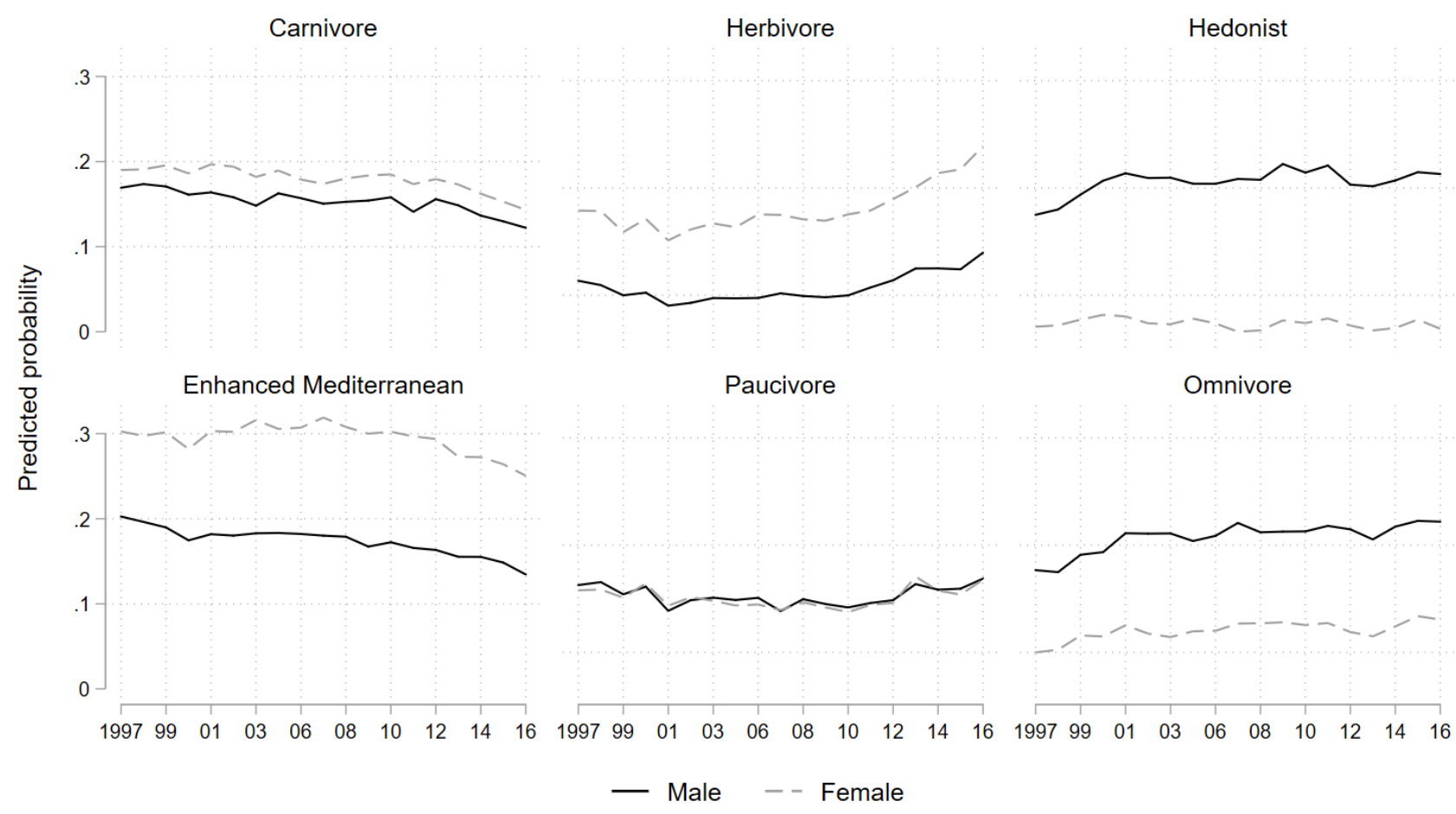

Figure 4 - Fractional logit models: predicted probabilities of adopting different dietary styles by gender and year. Source: ISTAT-MDS 1997-2016. See Table A8 in the supplemental material for the details of the average partial effects. 


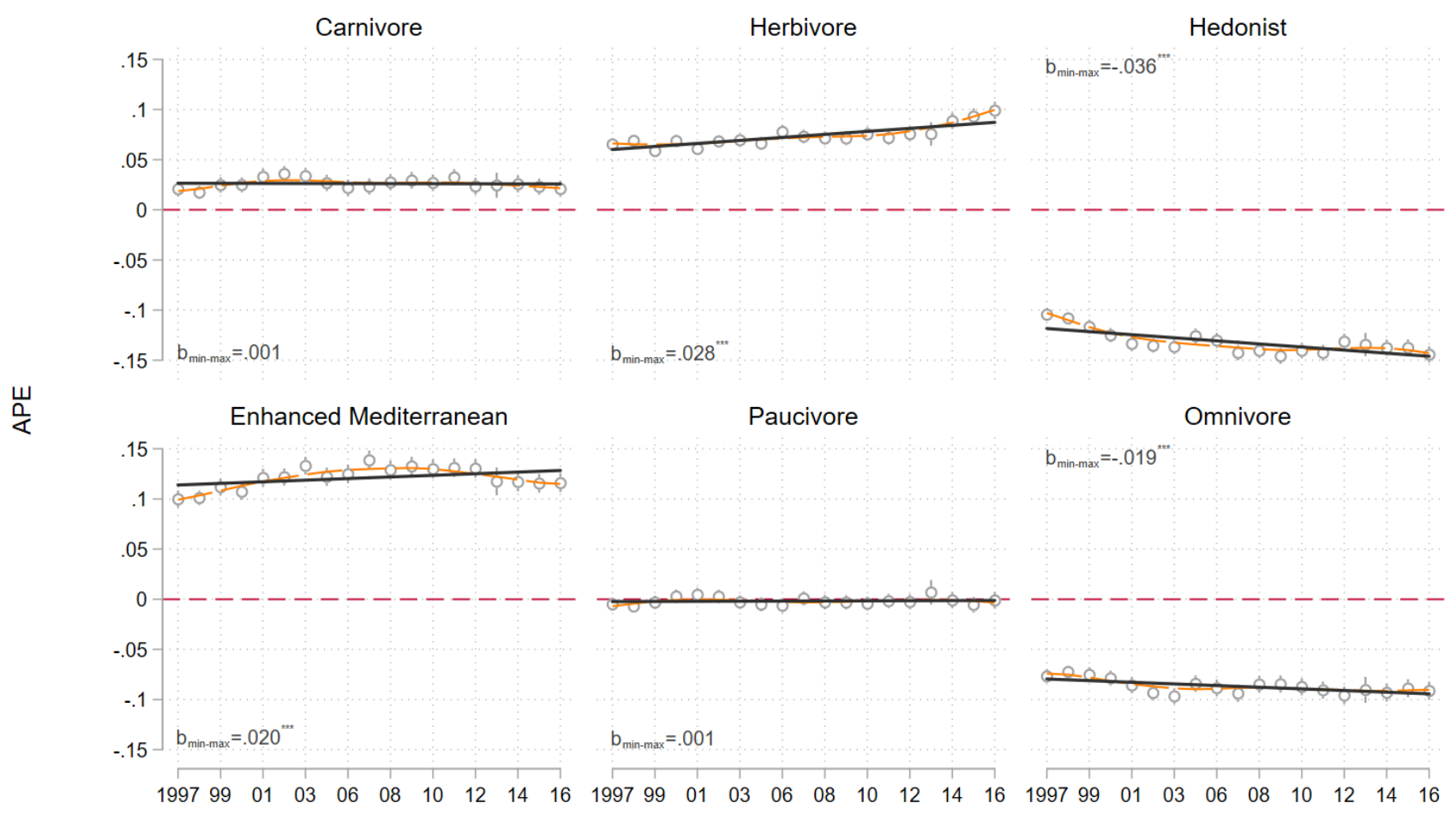

Fig. 5 - Average partial effect (and 95\% confidence intervals) from fractional logit models measuring the average differences between women versus men in the probability of adopting different dietary styles (grey dots): linear fit by variance weighted least square regression compared with lowess smoothed trend. Source: ISTAT-MDS 1997-2016. Note: in the graph we report the "range effect", which correspond to the total change in the average partial effect between 1997 and 2016, with associated level of statistical significance $(* \mathrm{p}<0.05 ; * * \mathrm{p}<0.01 ; * * * \mathrm{p}<0.001)$. 


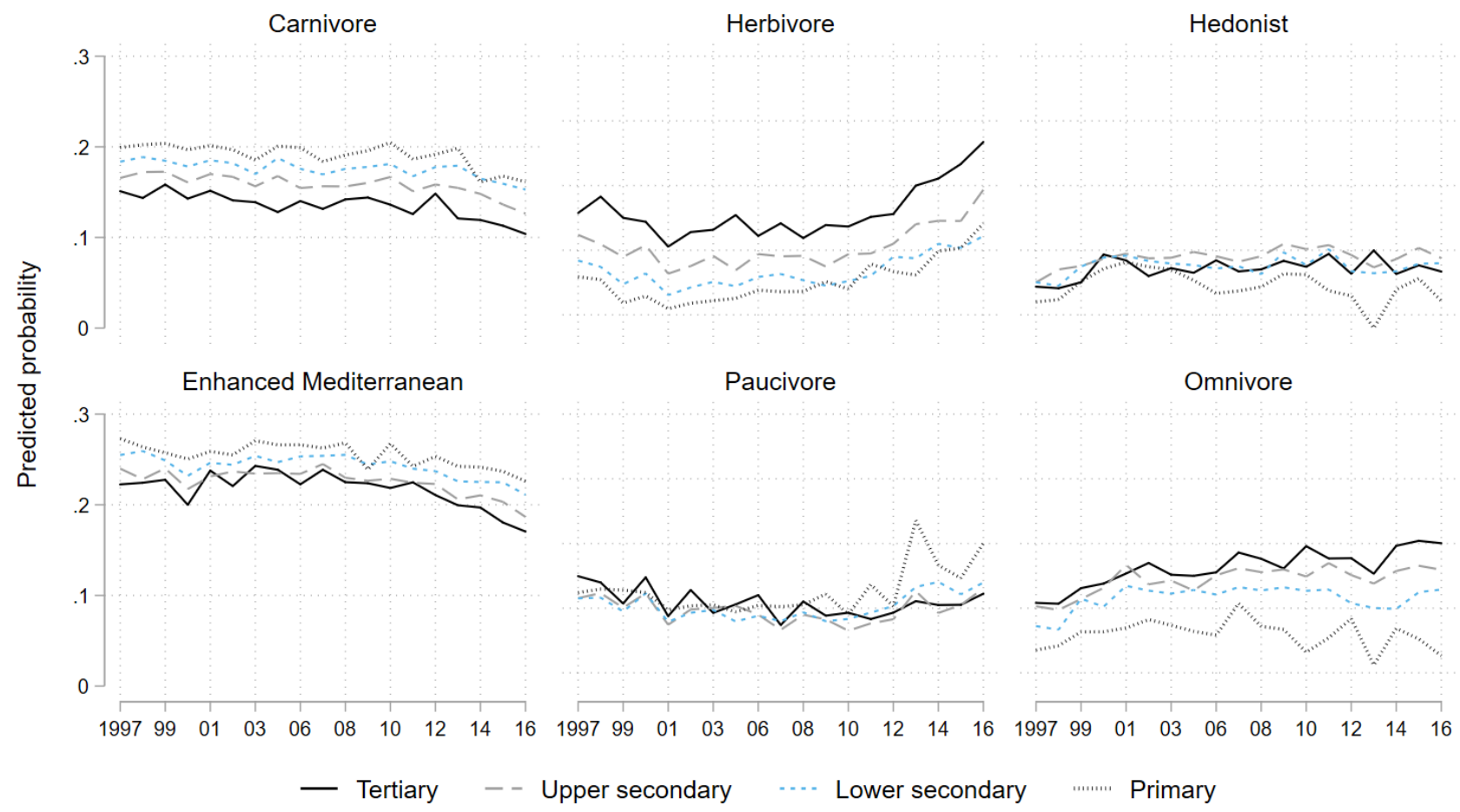

Figure 6 - Fractional logit models: predicted probabilities of adopting different dietary styles by education and year.

Source: ISTAT-MDS 1997-2016. See Table A9 in the supplemental material for the details of the average partial effects. 


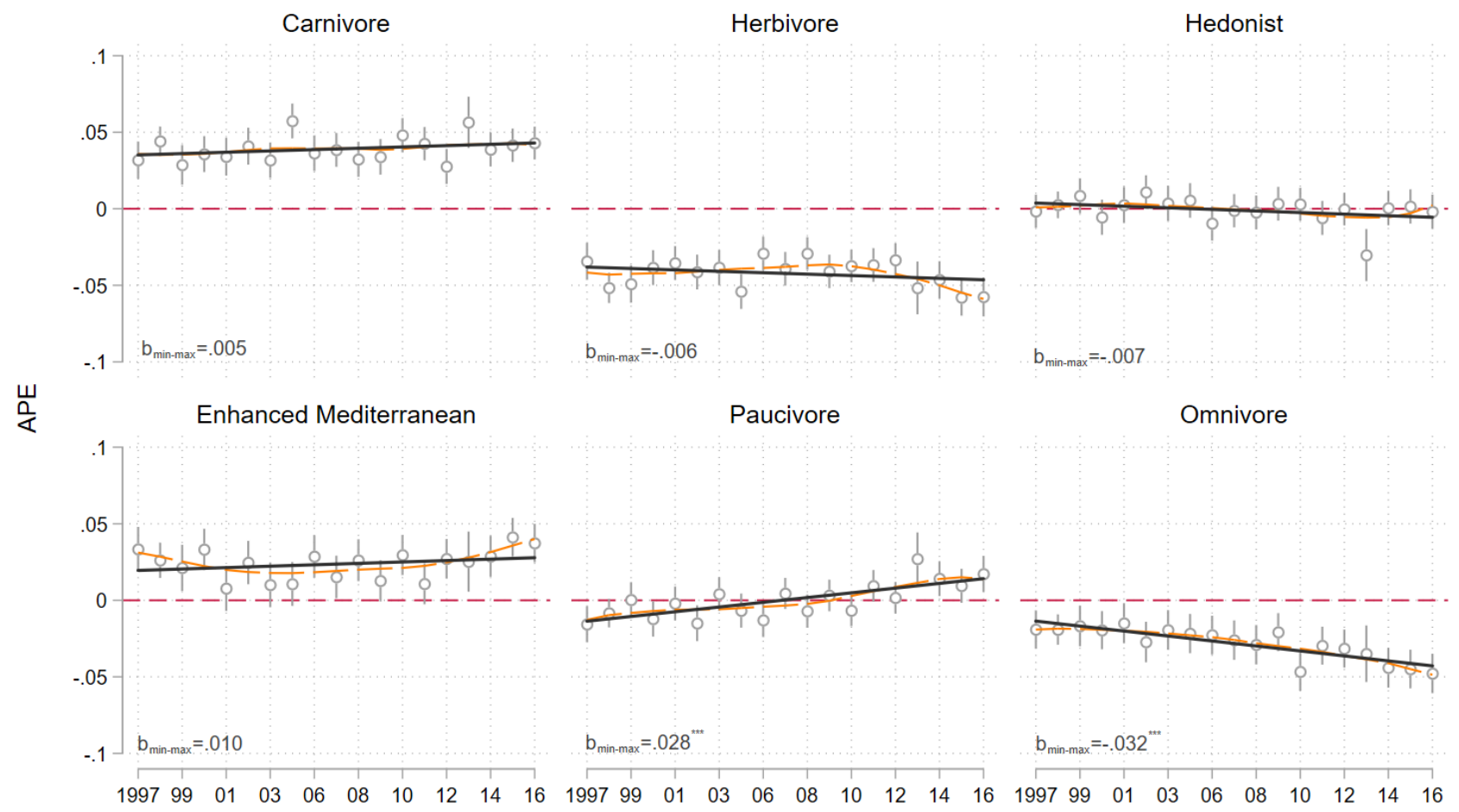

Fig. 7 - Fractional logit models: average difference between individuals with medium-lower education and tertiary educated in the probability of adopting different dietary styles. Source: ISTAT-MDS 1997-2016.

Note: in the graph we report the "range effect", which correspond to the total change in the average partial effect between 1997 and 2016, with associated level of statistical significance $(* \mathrm{p}<0.05 ; * * \mathrm{p}<0.01 ; * * * \mathrm{p}<0.001)$. 


\section{Supplemental material}

\begin{tabular}{rrr} 
Year & Frequency & Percentage \\
\hline 1997 & 29,277 & 6.08 \\
1998 & 40,305 & 8.37 \\
1999 & 28,001 & 5.82 \\
2000 & 29,733 & 6.18 \\
2001 & 27,183 & 5.65 \\
2002 & 28,672 & 5.96 \\
2003 & 27,707 & 5.76 \\
2005 & 25,190 & 5.23 \\
2006 & 24,755 & 5.14 \\
2007 & 24,370 & 5.06 \\
2008 & 24,549 & 5.1 \\
2009 & 23,988 & 4.98 \\
2010 & 24,571 & 5.1 \\
2011 & 24,093 & 5.01 \\
2012 & 23,519 & 4.89 \\
2013 & 10,096 & 2.1 \\
2014 & 21,851 & 4.54 \\
2015 & 22,325 & 4.64 \\
2016 & 21,174 & 4.4 \\
\hline Total & 481,359 & 100
\end{tabular}

Table A1. Sample numerosity by year.

Source: ISTAT-MDS 1997-2016. 
Table A2. Latent Class Analysis applied on a sample of individuals randomly extracted from their families. Marginal predicted means of the food items within each latent class. Pooled sample (N = 258,478). Source: ISTAT-MDS 1997-2016.

\begin{tabular}{|c|c|c|c|c|c|c|}
\hline & Carnivore & Herbivore & Hedonist & Enhanced Mediterranean & Paucivore & Omnivore \\
\hline Chicken & 0.945 & 0.524 & 0.913 & 0.949 & 0.458 & 0.926 \\
\hline Cured meat & 0.770 & 0.317 & 0.850 & 0.665 & 0.485 & 0.764 \\
\hline Beef & 0.933 & 0.212 & 0.902 & 0.911 & 0.285 & 0.875 \\
\hline Pork & 0.676 & 0.041 & 0.682 & 0.605 & 0.100 & 0.610 \\
\hline Fish & 0.632 & 0.538 & 0.596 & 0.687 & 0.312 & 0.684 \\
\hline Vegetables (leaf) & 0.077 & 0.917 & 0.081 & 0.896 & 0.141 & 0.875 \\
\hline Vegetables (fruit) & 0.038 & 0.801 & 0.032 & 0.766 & 0.061 & 0.758 \\
\hline Fruit & 0.665 & 0.921 & 0.598 & 0.933 & 0.624 & 0.899 \\
\hline Soft drinks & 0.413 & 0.301 & 0.748 & 0.346 & 0.441 & 0.673 \\
\hline Beer & 0.000 & 0.259 & 1.000 & 0.000 & 0.346 & 0.988 \\
\hline Wine & 0.405 & 0.478 & 0.861 & 0.411 & 0.525 & 0.874 \\
\hline Predicted probabilities & 0.167 & 0.149 & 0.136 & 0.235 & 0.150 & 0.164 \\
\hline
\end{tabular}




\begin{tabular}{llllllllll} 
Number of classes & $\mathbf{N}$ & Log likelihood & df & AIC & BIC & Entropy & Change in AIC Change in BIC Change in Entropy \\
\hline 1 & 481,359 & $-3,381,793$ & 11 & $6,763,608$ & $6,763,730$ & & & \\
2 & 481,359 & $-3,277,888$ & 23 & $6,555,822$ & $6,556,077$ & 0.619 & $207,785.900$ & $207,653.000$ \\
3 & 481,359 & $-3,188,508.3$ & 35 & $6,377,087$ & $6,377,475$ & 0.701 & $178,735.500$ & $178,602.400$ & 0.082 \\
4 & 481,359 & $-3,154,358.8$ & 47 & $6,308,812$ & $6,309,333$ & 0.756 & $68,274.900$ & $68,141.900$ & 0.054 \\
5 & 481,359 & $-3,127,976.6$ & 59 & $6,256,071$ & $6,256,725$ & 0.748 & $52,740.400$ & $52,607.400$ & -0.008 \\
6 & 481,359 & $-3,107,118$ & 71 & $6,214,378$ & $6,215,165$ & 0.775 & $41,693.200$ & $41,560.200$ & 0.027 \\
7 & 481,359 & $-3,098,151.2$ & 83 & $6,196,468$ & $6,197,388$ & 0.762 & $17,909.700$ & $17,776.600$ & -0.013 \\
8 & 481,359 & $-3,091,383$ & 94 & $6,182,954$ & $6,183,996$ & 0.763 & $13,514.400$ & $13,392.600$ & 0.001 \\
\hline
\end{tabular}

Table A3. Goodness of fit statistics for the latent class model: comparison of different solutions. Pooled sample (N=481,359). Source: ISTAT-MDS 1997-2016. 


\begin{tabular}{lllllll} 
Food items & Carnivore & Herbivore & Hedonist & $\begin{array}{l}\text { Enhanced } \\
\text { Mediterranean }\end{array}$ & Paucivore & Omnivore \\
\hline Chicken & 0.947 & 0.530 & 0.916 & 0.950 & 0.468 & 0.927 \\
Cured meat & 0.777 & 0.326 & 0.857 & 0.675 & 0.496 & 0.772 \\
Beef & 0.934 & 0.225 & 0.906 & 0.917 & 0.305 & 0.879 \\
Pork & 0.682 & 0.045 & 0.687 & 0.610 & 0.105 & 0.616 \\
Fish & 0.637 & 0.535 & 0.602 & 0.682 & 0.316 & 0.683 \\
Vegetables (leaf) & 0.077 & 0.915 & 0.084 & 0.896 & 0.145 & 0.877 \\
Vegetables (fruit) & 0.042 & 0.801 & 0.037 & 0.766 & 0.062 & 0.759 \\
Fruit & 0.672 & 0.922 & 0.608 & 0.933 & 0.633 & 0.898 \\
Soft drinks & 0.414 & 0.308 & 0.751 & 0.352 & 0.447 & 0.677 \\
Beer & 0.000 & 0.259 & 1.000 & 0.000 & 0.346 & 0.994 \\
Wine & 0.410 & 0.481 & 0.856 & 0.422 & 0.530 & 0.875 \\
\hline
\end{tabular}

Table A4. Marginal predicted means of the food items within each latent class. Pooled sample (N=481,359). Source: ISTAT-MDS $1997-2016$. 


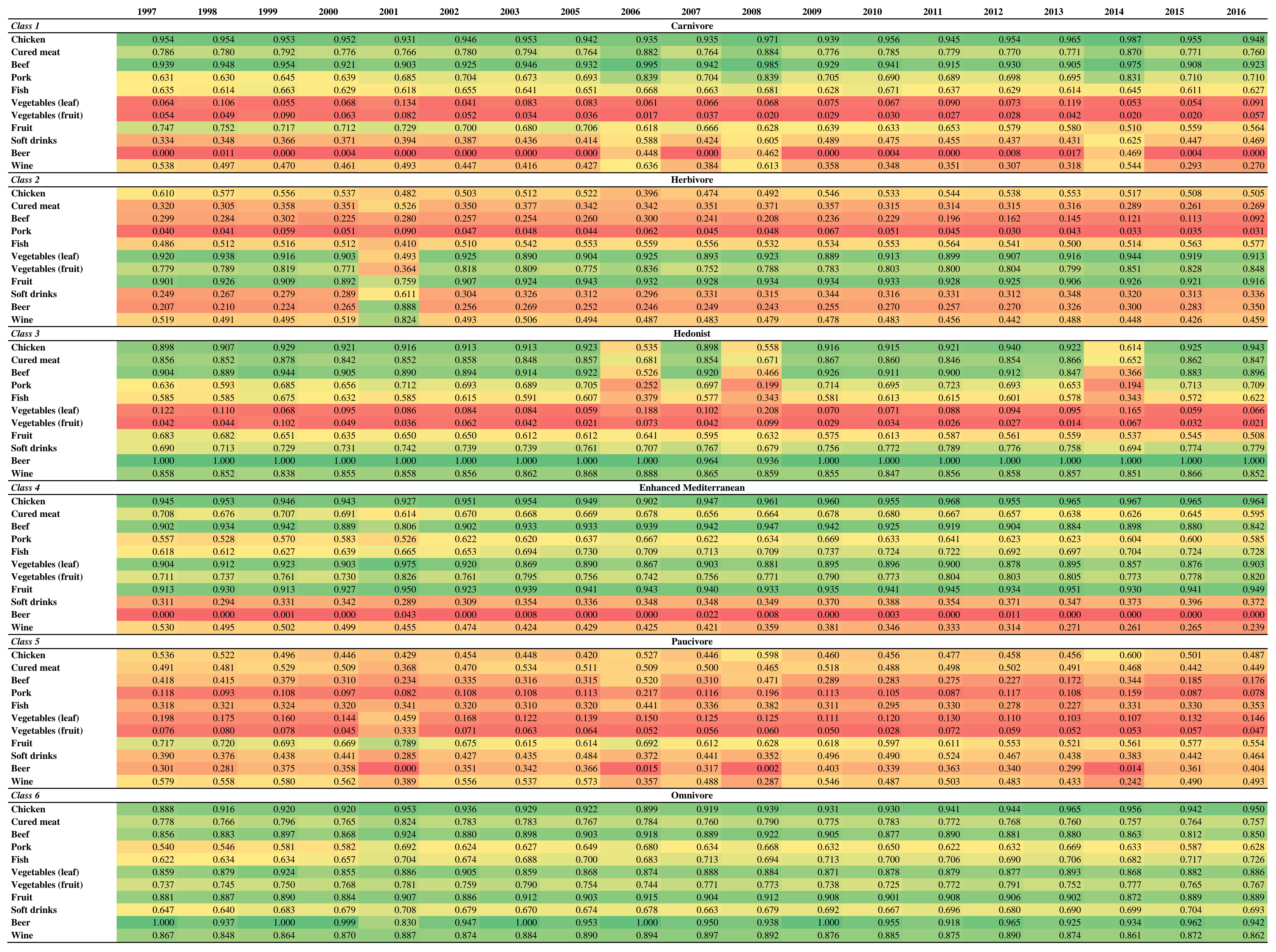

Table A5. Marginal predicted means of the food items within each latent class. Latent class models estimated on each single year. Source: ISTAT-MDS 1997-2016. 


\begin{tabular}{c|llllll} 
Year & Carnivore & Herbivore & Hedonist & $\begin{array}{l}\text { Enhanced } \\
\text { Mediterranean }\end{array}$ & Paucivore & Omnivore \\
\hline 1997 & 0.180 & 0.146 & 0.122 & 0.253 & 0.160 & 0.138 \\
1998 & 0.183 & 0.145 & 0.124 & 0.249 & 0.162 & 0.138 \\
1999 & 0.184 & 0.130 & 0.134 & 0.247 & 0.153 & 0.153 \\
2000 & 0.174 & 0.137 & 0.143 & 0.230 & 0.163 & 0.154 \\
2001 & 0.181 & 0.121 & 0.145 & 0.244 & 0.141 & 0.167 \\
2002 & 0.176 & 0.127 & 0.140 & 0.242 & 0.150 & 0.163 \\
2003 & 0.165 & 0.132 & 0.140 & 0.250 & 0.150 & 0.162 \\
2005 & 0.176 & 0.131 & 0.140 & 0.246 & 0.146 & 0.161 \\
2006 & 0.168 & 0.137 & 0.138 & 0.246 & 0.148 & 0.164 \\
2007 & 0.162 & 0.139 & 0.136 & 0.251 & 0.139 & 0.173 \\
2008 & 0.167 & 0.136 & 0.136 & 0.245 & 0.148 & 0.169 \\
2009 & 0.169 & 0.135 & 0.148 & 0.235 & 0.143 & 0.170 \\
2010 & 0.172 & 0.139 & 0.142 & 0.239 & 0.140 & 0.168 \\
2011 & 0.158 & 0.144 & 0.149 & 0.233 & 0.145 & 0.172 \\
2012 & 0.168 & 0.152 & 0.136 & 0.230 & 0.147 & 0.166 \\
2013 & 0.161 & 0.163 & 0.134 & 0.215 & 0.167 & 0.160 \\
2014 & 0.150 & 0.171 & 0.137 & 0.216 & 0.158 & 0.169 \\
2015 & 0.142 & 0.173 & 0.144 & 0.208 & 0.157 & 0.177 \\
2016 & 0.133 & 0.191 & 0.139 & 0.194 & 0.168 & 0.175 \\
\hline
\end{tabular}

Table A6. Predicted probabilities of latent profiles over time. Pooled sample (N=481,359). Source: ISTAT-MDS 1997-2016. 


\begin{tabular}{|c|c|c|c|c|c|c|}
\hline Variables & Carnivore & Herbivore & Hedonist & $\begin{array}{l}\text { Enhanced } \\
\text { Mediterranean }\end{array}$ & Paucivore & Omnivore \\
\hline \multicolumn{7}{|l|}{ Education } \\
\hline Upper secondary [ref. Tertiary] & $\begin{array}{l}0.179 * * * \\
(0.0119)\end{array}$ & $\begin{array}{l}-0.204 * * * \\
(0.0104)\end{array}$ & $\begin{array}{l}0.0845^{* * * *} \\
(0.0122)\end{array}$ & $\begin{array}{l}0.0461 * * * \\
(0.0103)\end{array}$ & $\begin{array}{l}-0.0413 * * * \\
(0.0105)\end{array}$ & $\begin{array}{l}-0.0690 \text { **** } \\
(0.0111)\end{array}$ \\
\hline Lower secondary & $\begin{array}{l}0.303 * * * \\
(0.0116)\end{array}$ & $\begin{array}{l}-0.358 * * * \\
(0.0103)\end{array}$ & $\begin{array}{l}0.0280^{* *} \\
(0.0121)\end{array}$ & $\begin{array}{l}0.147 * * * \\
(0.0101)\end{array}$ & $\begin{array}{l}-0.0226 * * \\
(0.0104)\end{array}$ & $\begin{array}{l}-0.169 * * * \\
(0.0110)\end{array}$ \\
\hline Primary & $\begin{array}{l}0.414 * * * \\
(0.0139)\end{array}$ & $\begin{array}{l}-0.451 * * * \\
(0.0131)\end{array}$ & $\begin{array}{l}-0.100 * * * \\
(0.0164)\end{array}$ & $\begin{array}{l}0.223 * * * \\
(0.0120)\end{array}$ & $\begin{array}{l}0.0314 * * \\
(0.0129)\end{array}$ & $\begin{array}{l}-0.388 * * * \\
(0.0149)\end{array}$ \\
\hline \multicolumn{7}{|l|}{ Gender } \\
\hline Female [ref. Male] & $\begin{array}{l}0.190^{* * *} \\
(0.00684)\end{array}$ & $\begin{array}{l}0.619 * * * \\
(0.00690)\end{array}$ & $\begin{array}{l}-1.190 * * * \\
(0.00829)\end{array}$ & $\begin{array}{l}0.691 * * * \\
(0.00621)\end{array}$ & $\begin{array}{c}-0.0165^{* *} \\
(0.00650)\end{array}$ & $\begin{array}{l}-0.651 * * * \\
(0.00731)\end{array}$ \\
\hline \multicolumn{7}{|l|}{ Area of residence } \\
\hline Centre [ref. North] & $\begin{array}{l}0.341 * * * \\
(0.00986)\end{array}$ & $\begin{array}{l}-0.385 * * * \\
(0.00927)\end{array}$ & $\begin{array}{l}0.0281 * * \\
(0.0110)\end{array}$ & $\begin{array}{l}0.293 * * * \\
(0.00810)\end{array}$ & $\begin{array}{l}-0.326 * * * \\
(0.00960)\end{array}$ & $\begin{array}{l}-0.0881 * * * \\
(0.00964)\end{array}$ \\
\hline South & $\begin{array}{l}0.719 * * * \\
(0.00757)\end{array}$ & $\begin{array}{l}-0.550 * * * \\
(0.00751)\end{array}$ & $\begin{array}{l}0.312 * * * \\
(0.00832)\end{array}$ & $\begin{array}{l}-0.164 * * * \\
(0.00678)\end{array}$ & $\begin{array}{l}0.112 * * * \\
(0.00696)\end{array}$ & $\begin{array}{l}-0.435 * * * \\
(0.00801)\end{array}$ \\
\hline \multicolumn{7}{|l|}{ Age } \\
\hline $35-44$ [ref. 25-34] & $\begin{array}{l}-0.0572 * * * \\
(0.0101)\end{array}$ & $\begin{array}{l}0.178 * * * \\
(0.0104)\end{array}$ & $\begin{array}{l}-0.224 * * * \\
(0.0103)\end{array}$ & $\begin{array}{l}0.119 * * * \\
(0.00939)\end{array}$ & $\begin{array}{l}0.0256 * * * \\
(0.00949)\end{array}$ & $\begin{array}{l}-0.0377 \text { *** } \\
(0.0100)\end{array}$ \\
\hline $45-44$ & $\begin{array}{l}-0.0948 * * * \\
(0.0107)\end{array}$ & $\begin{array}{l}0.398^{* * *} \\
(0.0108)\end{array}$ & $\begin{array}{l}-0.547 * * * \\
(0.0116)\end{array}$ & $\begin{array}{l}0.298 * * * \\
(0.00971)\end{array}$ & $\begin{array}{l}0.0115 \\
(0.0102)\end{array}$ & $\begin{array}{l}-0.123 * * * \\
(0.0108)\end{array}$ \\
\hline $55-59$ & $\begin{array}{l}-0.151 * * * \\
(0.0134)\end{array}$ & $\begin{array}{l}0.593 * * * \\
(0.0131)\end{array}$ & $\begin{array}{l}-0.844 * * * \\
(0.0161)\end{array}$ & $\begin{array}{l}0.478 * * * \\
(0.0117)\end{array}$ & $\begin{array}{l}-0.00517 \\
(0.0129)\end{array}$ & $\begin{array}{l}-0.298 * * * \\
(0.0144)\end{array}$ \\
\hline $60-64$ & $\begin{array}{l}-0.178 * * * \\
(0.0141)\end{array}$ & $\begin{array}{l}0.726 * * * \\
(0.0136)\end{array}$ & $\begin{array}{l}-1.135^{* * *} \\
(0.0184)\end{array}$ & $\begin{array}{l}0.586 * * * \\
(0.0122)\end{array}$ & $\begin{array}{l}-0.0305 * * \\
(0.0136)\end{array}$ & $\begin{array}{l}-0.413 * * * \\
(0.0157)\end{array}$ \\
\hline \multicolumn{7}{|l|}{ Year } \\
\hline 1998 [ref. 1997] & $\begin{array}{l}0.0171 \\
(0.0170)\end{array}$ & $\begin{array}{l}-0.0330 * \\
(0.0171)\end{array}$ & $\begin{array}{l}0.0316 \\
(0.0209)\end{array}$ & $\begin{array}{l}-0.0251 \\
(0.0154)\end{array}$ & $\begin{array}{l}0.00669 \\
(0.0161)\end{array}$ & $\begin{array}{l}0.00528 \\
(0.0198)\end{array}$ \\
\hline 1999 & $\begin{array}{l}0.0190 \\
(0.0186)\end{array}$ & $\begin{array}{l}-0.148 * * * \\
(0.0190)\end{array}$ & $\begin{array}{l}0.118 * * * \\
(0.0224)\end{array}$ & $\begin{array}{l}-0.0326^{*} \\
(0.0169)\end{array}$ & $\begin{array}{l}-0.0626^{* * *} \\
(0.0179)\end{array}$ & $\begin{array}{l}0.129 * * * \\
(0.0212)\end{array}$ \\
\hline 2000 & $\begin{array}{l}-0.0216 \\
(0.0185)\end{array}$ & $\begin{array}{l}-0.106 * * * \\
(0.0186)\end{array}$ & $\begin{array}{l}0.199 * * * \\
(0.0219)\end{array}$ & $\begin{array}{l}-0.130 * * * \\
(0.0168)\end{array}$ & $\begin{array}{l}0.0145 \\
(0.0174)\end{array}$ & $\begin{array}{l}0.119 * * * \\
(0.0208)\end{array}$ \\
\hline 2001 & $\begin{array}{l}0.0137 \\
(0.0189)\end{array}$ & $\begin{array}{l}-0.245^{* * *} \\
(0.0196)\end{array}$ & $\begin{array}{l}0.216^{* * * *} \\
(0.0223)\end{array}$ & $\begin{array}{l}-0.0474 * * * \\
(0.0171)\end{array}$ & $\begin{array}{l}-0.153 * * * \\
(0.0185)\end{array}$ & $\begin{array}{l}0.233 * * * \\
(0.0210)\end{array}$ \\
\hline 2002 & $\begin{array}{l}-0.00668 \\
(0.0188)\end{array}$ & $\begin{array}{l}-0.197 * * * \\
(0.0191)\end{array}$ & $\begin{array}{l}0.179 * * * \\
(0.0221)\end{array}$ & $\begin{array}{l}-0.0548 * * * \\
(0.0169)\end{array}$ & $\begin{array}{l}-0.0838^{* * *} \\
(0.0180)\end{array}$ & $\begin{array}{l}0.198 * * * \\
(0.0209)\end{array}$ \\
\hline 2003 & $\begin{array}{l}-0.0881 * * * \\
(0.0191)\end{array}$ & $\begin{array}{l}-0.155^{* * * *} \\
(0.0192)\end{array}$ & $\begin{array}{l}0.172 * * * \\
(0.0224)\end{array}$ & $\begin{array}{l}-0.00222 \\
(0.0170)\end{array}$ & $\begin{array}{l}-0.0909 * * * * \\
(0.0182)\end{array}$ & $\begin{array}{l}0.189 * * * \\
(0.0211)\end{array}$ \\
\hline 2005 & $\begin{array}{l}-0.00617 \\
(0.0194)\end{array}$ & $\begin{array}{l}-0.178 * * * \\
(0.0198)\end{array}$ & $\begin{array}{l}0.168 * * * \\
(0.0230)\end{array}$ & $\begin{array}{l}-0.0215 \\
(0.0175)\end{array}$ & $\begin{array}{l}-0.119 * * * \\
(0.0188)\end{array}$ & $\begin{array}{l}0.178 * * * \\
(0.0217)\end{array}$ \\
\hline 2006 & $\begin{array}{l}-0.0535^{* * *} \\
(0.0197)\end{array}$ & $\begin{array}{l}-0.137 * * * \\
(0.0198)\end{array}$ & $\begin{array}{l}0.152 * * * \\
(0.0231)\end{array}$ & $\begin{array}{l}-0.0196 \\
(0.0176)\end{array}$ & $\begin{array}{l}-0.109 * * * \\
(0.0188)\end{array}$ & $\begin{array}{l}0.193 * * * \\
(0.0217)\end{array}$ \\
\hline 2007 & $\begin{array}{l}-0.0947 * * * \\
(0.0200)\end{array}$ & $\begin{array}{l}-0.125 * * * \\
(0.0198)\end{array}$ & $\begin{array}{l}0.142 * * * \\
(0.0232)\end{array}$ & $\begin{array}{l}0.00710 \\
(0.0177)\end{array}$ & $\begin{array}{l}-0.180 * * * \\
(0.0192)\end{array}$ & $\begin{array}{l}0.262 * * * \\
(0.0216)\end{array}$ \\
\hline 2008 & $\begin{array}{l}-0.0550 * * * \\
(0.0199)\end{array}$ & $\begin{array}{l}-0.163 * * * \\
(0.0199)\end{array}$ & $\begin{array}{l}0.145^{* * * *} \\
(0.0233)\end{array}$ & $\begin{array}{l}-0.0223 \\
(0.0177)\end{array}$ & $\begin{array}{l}-0.108 * * * \\
(0.0190)\end{array}$ & $\begin{array}{l}0.228 * * * \\
(0.0217)\end{array}$ \\
\hline 2009 & $\begin{array}{c}-0.0333 * \\
(0.0201)\end{array}$ & $\begin{array}{l}-0.180 * * * \\
(0.0202)\end{array}$ & $\begin{array}{l}0.251 * * * \\
(0.0230)\end{array}$ & $\begin{array}{l}-0.0749 * * * \\
(0.0180)\end{array}$ & $\begin{array}{l}-0.147 * * * \\
(0.0192)\end{array}$ & $\begin{array}{l}0.233 * * * \\
(0.0217)\end{array}$ \\
\hline 2010 & $\begin{array}{l}-0.00558 \\
(0.0198)\end{array}$ & $\begin{array}{l}-0.165 * * * \\
(0.0200)\end{array}$ & $\begin{array}{l}0.217 * * * \\
(0.0231)\end{array}$ & $\begin{array}{l}-0.0574 * * * \\
(0.0178)\end{array}$ & $\begin{array}{l}-0.177 * * * \\
(0.0193)\end{array}$ & $\begin{array}{l}0.224 * * * \\
(0.0216)\end{array}$ \\
\hline 2011 & $\begin{array}{l}-0.114 * * * \\
(0.0203)\end{array}$ & $\begin{array}{l}-0.119 * * * \\
(0.0199)\end{array}$ & $\begin{array}{l}0.269 * * * \\
(0.0230)\end{array}$ & $\begin{array}{l}-0.0880 * * * \\
(0.0181)\end{array}$ & $\begin{array}{l}-0.138 * * * \\
(0.0192)\end{array}$ & $\begin{array}{l}0.252 * * * \\
(0.0217)\end{array}$ \\
\hline 2012 & $\begin{array}{l}-0.0243 \\
(0.0203)\end{array}$ & $\begin{array}{l}-0.0644 * * * \\
(0.0199)\end{array}$ & $\begin{array}{l}0.168 * * * \\
(0.0237)\end{array}$ & $\begin{array}{l}-0.105 * * * \\
(0.0182)\end{array}$ & $\begin{array}{l}-0.120 * * * \\
(0.0194)\end{array}$ & $\begin{array}{l}0.205 * * * \\
(0.0220)\end{array}$ \\
\hline 2013 & $\begin{array}{l}-0.0727 * * * \\
(0.0271)\end{array}$ & $\begin{array}{l}0.0119 \\
(0.0260)\end{array}$ & $\begin{array}{l}0.131 * * * \\
(0.0311)\end{array}$ & $\begin{array}{l}-0.178 * * * \\
(0.0247)\end{array}$ & $\begin{array}{l}0.0288 \\
(0.0252)\end{array}$ & $\begin{array}{l}0.147 * * * \\
(0.0289)\end{array}$ \\
\hline 2014 & $\begin{array}{l}-0.146^{* * *} \\
(0.0214)\end{array}$ & $\begin{array}{l}0.0430 * * \\
(0.0200)\end{array}$ & $\begin{array}{l}0.180 * * * \\
(0.0241)\end{array}$ & $\begin{array}{l}-0.184 * * * \\
(0.0190)\end{array}$ & $\begin{array}{c}-0.0384 * \\
(0.0197)\end{array}$ & $\begin{array}{l}0.222 * * * \\
(0.0224)\end{array}$ \\
\hline 2015 & $\begin{array}{l}-0.204 * * * \\
(0.0215)\end{array}$ & $\begin{array}{l}0.0443 * * \\
(0.0198)\end{array}$ & $\begin{array}{l}0.250 * * * \\
(0.0238)\end{array}$ & $\begin{array}{l}-0.230 * * * \\
(0.0190)\end{array}$ & $\begin{array}{l}-0.0495^{* *} \\
(0.0196)\end{array}$ & $\begin{array}{l}0.274 * * * \\
(0.0220)\end{array}$ \\
\hline 2016 & $\begin{array}{l}-0.279 * * * \\
(0.0222)\end{array}$ & $\begin{array}{l}0.170 * * * \\
(0.0198)\end{array}$ & $\begin{array}{l}0.204 * * * \\
(0.0242)\end{array}$ & $\begin{array}{l}-0.315^{* * *} \\
(0.0196)\end{array}$ & $\begin{array}{l}0.0331 * \\
(0.0197)\end{array}$ & $\begin{array}{l}0.262 * * * \\
(0.0224)\end{array}$ \\
\hline \multicolumn{7}{|l|}{ Marital status } \\
\hline Married [ref. Single] & $\begin{array}{l}0.165 * * * \\
(0.00942)\end{array}$ & $\begin{array}{l}-0.227 * * * \\
(0.00909)\end{array}$ & $\begin{array}{l}0.0345^{* * * *} \\
(0.00967)\end{array}$ & $\begin{array}{l}0.138 * * * \\
(0.00844)\end{array}$ & $\begin{array}{c}-0.183 * * * \\
(0.00867)\end{array}$ & $\begin{array}{l}0.0605^{* * *} \\
(0.00913)\end{array}$ \\
\hline Separated/Divorced & $\begin{array}{l}0.0557 * * * \\
(0.0157)\end{array}$ & $\begin{array}{l}-0.0292 * * \\
(0.0141)\end{array}$ & $\begin{array}{l}0.0533 * * * \\
(0.0169)\end{array}$ & $\begin{array}{l}-0.0690 * * * \\
(0.0139)\end{array}$ & $\begin{array}{l}0.00846 \\
(0.0140)\end{array}$ & $\begin{array}{l}0.0407 * * * \\
(0.0155)\end{array}$ \\
\hline Widow & $\begin{array}{l}0.166^{* * *} \\
(0.0218)\end{array}$ & $\begin{array}{l}-0.165 * * * \\
(0.0205)\end{array}$ & $\begin{array}{l}-0.0161 \\
(0.0342)\end{array}$ & $\begin{array}{l}0.00269 \\
(0.0188)\end{array}$ & $\begin{array}{l}-0.0891 \text { *** } \\
(0.0214)\end{array}$ & $\begin{array}{l}-0.0942 * * * \\
(0.0287)\end{array}$ \\
\hline Constant & $\begin{array}{l}-2.317 * * * \\
(0.0185)\end{array}$ & $\begin{array}{l}-1.671 * * * \\
(0.0174)\end{array}$ & $\begin{array}{l}-1.325^{* * * *} \\
(0.0204)\end{array}$ & $\begin{array}{l}-1.912 * * * \\
(0.0167)\end{array}$ & $\begin{array}{l}-1.499 * * * \\
(0.0167)\end{array}$ & $\begin{array}{l}-1.139 * * * \\
(0.0192)\end{array}$ \\
\hline Observations & 481,359 & 481,359 & 481,359 & 481,359 & 481,359 & 481,359 \\
\hline
\end{tabular}

Robust standard errors in parentheses *** $\mathrm{p}<0.01, * * \mathrm{p}<0.05, * \mathrm{p}<0.1$

Table A7. Fractional logistic regression on the probability of endorsing the 5 food profiles. Pooled sample (N=481,359). Source: ISTAT-MDS 19972016. 


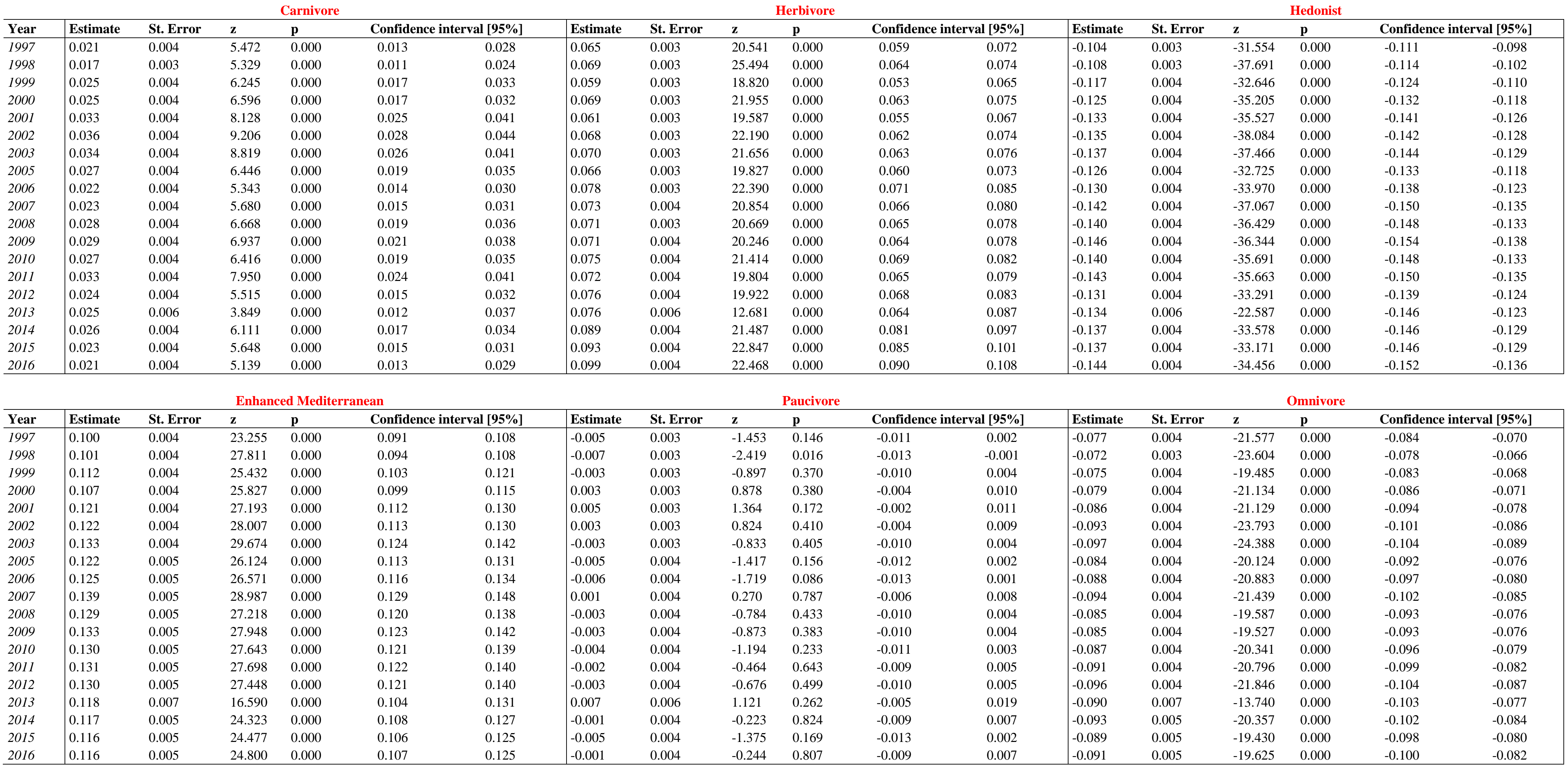

Table A8. Average partial effect (and 95\% confidence intervals) from fractional logit models measuring average difference between females and males in the probability of adopting different dietary styles. Source: ISTAT-MDS 1997-2016. 


\begin{tabular}{|c|c|c|c|c|c|c|c|c|c|c|c|c|c|c|c|c|c|c|}
\hline \multirow{3}{*}{$\begin{array}{l}\text { Year } \\
1997\end{array}$} & \multicolumn{6}{|c|}{ Carnivore } & \multicolumn{6}{|c|}{ Herbivore } & \multicolumn{6}{|c|}{ Hedonist } \\
\hline & \multirow{2}{*}{\begin{tabular}{|l|} 
Estimate \\
0.032
\end{tabular}} & \multirow{2}{*}{$\begin{array}{l}\text { St. Error } \\
0.006\end{array}$} & \multirow{2}{*}{$\begin{array}{l}\mathrm{z} \\
5.135\end{array}$} & \multirow{2}{*}{$\begin{array}{l}\mathbf{p} \\
0.000\end{array}$} & \multicolumn{2}{|c|}{ Confidence interval [95\%] } & \multirow{2}{*}{\begin{tabular}{|l|} 
Estimate \\
-0.034
\end{tabular}} & \multirow{2}{*}{$\begin{array}{l}\text { St. Error } \\
0.006\end{array}$} & \multirow{2}{*}{$\begin{array}{l}\mathbf{z} \\
-5.561\end{array}$} & \multirow{2}{*}{$\begin{array}{l}\mathbf{p} \\
0.000\end{array}$} & \multicolumn{2}{|c|}{ Confidence interval [95\%] } & \multirow{2}{*}{\begin{tabular}{|l} 
Estimate \\
-0.002
\end{tabular}} & \multirow{2}{*}{$\begin{array}{l}\text { St. Error } \\
0.006\end{array}$} & \multirow{2}{*}{$\begin{array}{l}\mathbf{z} \\
-0.298\end{array}$} & \multirow{2}{*}{$\begin{array}{l}\mathbf{p} \\
0.766\end{array}$} & \multicolumn{2}{|c|}{ Confidence interval [95\%] } \\
\hline & & & & & 0.020 & 0.044 & & & & & -0.046 & -0.022 & & & & & -0.012 & 0.009 \\
\hline 1998 & 0.044 & 0.005 & 8.995 & 0.000 & 0.035 & 0.054 & -0.052 & 0.005 & -10.244 & 0.000 & -0.062 & -0.042 & 0.003 & 0.004 & 0.572 & 0.567 & -0.006 & 0.011 \\
\hline 1999 & 0.029 & 0.007 & 4.337 & 0.000 & 0.016 & 0.042 & -0.049 & 0.006 & -7.872 & 0.000 & -0.061 & -0.037 & 0.008 & 0.006 & 1.459 & 0.145 & -0.003 & 0.020 \\
\hline 2000 & 0.036 & 0.006 & 5.965 & 0.000 & 0.024 & 0.047 & -0.038 & 0.006 & -6.622 & 0.000 & -0.050 & -0.027 & -0.006 & 0.006 & -0.944 & 0.345 & -0.017 & 0.006 \\
\hline 2001 & 0.034 & 0.006 & 5.407 & 0.000 & 0.022 & 0.046 & -0.035 & 0.006 & -6.283 & 0.000 & -0.047 & -0.024 & 0.002 & 0.006 & 0.409 & 0.683 & -0.009 & 0.014 \\
\hline 2002 & 0.041 & 0.006 & 6.649 & 0.000 & 0.029 & 0.053 & -0.041 & 0.006 & -7.133 & 0.000 & -0.053 & -0.030 & 0.011 & 0.006 & 1.936 & 0.053 & 0.000 & 0.022 \\
\hline 2003 & 0.032 & 0.006 & 5.378 & 0.000 & 0.020 & 0.043 & -0.038 & 0.006 & -6.608 & 0.000 & -0.050 & -0.027 & 0.004 & 0.006 & 0.607 & 0.544 & -0.008 & 0.015 \\
\hline 2005 & 0.057 & 0.006 & 9.902 & 0.000 & 0.046 & 0.069 & -0.054 & 0.006 & -9.281 & 0.000 & -0.065 & -0.043 & 0.005 & 0.006 & 0.940 & 0.347 & -0.006 & 0.017 \\
\hline 2006 & 0.036 & 0.006 & 6.130 & 0.000 & 0.025 & 0.048 & $\mid-0.029$ & 0.006 & -5.221 & 0.000 & -0.040 & -0.018 & -0.010 & 0.006 & -1.661 & 0.097 & -0.021 & 0.002 \\
\hline 2007 & 0.038 & 0.006 & 6.815 & 0.000 & 0.027 & 0.049 & $\mid$ & 0.006 & -6.980 & 0.000 & -0.050 & -0.028 & -0.001 & 0.006 & -0.228 & 0.820 & -0.012 & 0.010 \\
\hline 2008 & 0.032 & 0.006 & 5.510 & 0.000 & 0.021 & 0.044 & $\mid-0.029$ & 0.005 & -5.349 & 0.000 & -0.040 & -0.019 & -0.002 & 0.006 & -0.421 & 0.674 & -0.013 & 0.009 \\
\hline 2009 & 0.034 & 0.006 & 5.708 & 0.000 & 0.022 & 0.046 & -0.041 & 0.006 & -7.343 & 0.000 & -0.052 & -0.030 & 0.003 & 0.006 & 0.582 & 0.561 & -0.008 & 0.014 \\
\hline 2010 & 0.048 & 0.006 & 8.403 & 0.000 & 0.037 & 0.059 & $\mid-0.037$ & 0.005 & -6.914 & 0.000 & -0.048 & -0.027 & 0.003 & 0.005 & 0.546 & 0.585 & -0.008 & 0.014 \\
\hline 2011 & 0.043 & 0.006 & 7.669 & 0.000 & 0.032 & 0.053 & $\mid-0.037$ & 0.006 & -6.544 & 0.000 & -0.048 & -0.026 & -0.006 & 0.006 & -1.061 & 0.289 & -0.017 & 0.005 \\
\hline 2012 & 0.028 & 0.006 & 4.735 & 0.000 & 0.016 & 0.039 & \begin{tabular}{|l}
-0.034 \\
\end{tabular} & 0.006 & -6.056 & 0.000 & -0.044 & -0.023 & 0.000 & 0.005 & -0.049 & 0.961 & -0.011 & 0.010 \\
\hline 2013 & 0.056 & 0.009 & 6.610 & 0.000 & 0.040 & 0.073 & -0.052 & 0.009 & -5.876 & 0.000 & -0.069 & -0.034 & -0.030 & 0.009 & -3.488 & 0.000 & -0.047 & -0.013 \\
\hline 2014 & 0.039 & 0.006 & 6.824 & 0.000 & 0.028 & 0.050 & $\mid-0.046$ & 0.006 & -7.494 & 0.000 & -0.059 & -0.034 & 0.000 & 0.006 & 0.084 & 0.933 & -0.011 & 0.012 \\
\hline 2015 & 0.041 & 0.006 & 7.468 & 0.000 & 0.031 & 0.052 & $\mid-0.058$ & 0.006 & -9.560 & 0.000 & -0.070 & -0.046 & 0.002 & 0.006 & 0.262 & 0.793 & -0.010 & 0.013 \\
\hline 2016 & 0.043 & 0.005 & 7.838 & 0.000 & 0.032 & 0.054 & -0.058 & 0.007 & -8.855 & 0.000 & -0.070 & -0.045 & -0.002 & 0.006 & -0.335 & 0.737 & -0.013 & 0.009 \\
\hline & & & Enhar & ced Medi & gean & & & & & aucivor & & & & & & Omnivor & & \\
\hline Year & Estimate & St. Error & $\mathrm{z}$ & $\mathbf{p}$ & Confiden & {$[95 \%]$} & Estimate & St. Error & $\mathbf{z}$ & $\mathbf{p}$ & Confide & {$[$ [95\%] } & Estimate & St. Error & $\mathrm{z}$ & $\mathbf{p}$ & Confide & {$[95 \%]$} \\
\hline 1997 & 0.033 & 0.007 & 4.488 & 0.000 & 0.019 & 0.048 & \begin{tabular}{|l|}
-0.016 \\
\end{tabular} & 0.006 & -2.603 & 0.009 & -0.027 & -0.004 & \begin{tabular}{|l|}
-0.019 \\
\end{tabular} & 0.006 & -2.995 & 0.003 & -0.032 & -0.007 \\
\hline 1998 & 0.026 & 0.006 & 4.444 & 0.000 & 0.015 & 0.038 & $\mid-0.008$ & 0.005 & -1.752 & 0.080 & -0.018 & 0.001 & -0.019 & 0.005 & -3.782 & 0.000 & -0.029 & -0.009 \\
\hline 1999 & 0.021 & 0.008 & 2.761 & 0.006 & 0.006 & 0.036 & 0.000 & 0.006 & 0.052 & 0.959 & -0.011 & 0.012 & -0.017 & 0.007 & -2.482 & 0.013 & -0.030 & -0.004 \\
\hline 2000 & 0.033 & 0.007 & 4.820 & 0.000 & 0.020 & 0.047 & -0.012 & 0.006 & -2.067 & 0.039 & -0.024 & -0.001 & -0.020 & 0.006 & -3.070 & 0.002 & -0.032 & -0.007 \\
\hline 2001 & 0.008 & 0.008 & 1.035 & 0.301 & -0.007 & 0.022 & -0.002 & 0.006 & -0.357 & 0.721 & -0.013 & 0.009 & -0.015 & 0.007 & -2.240 & 0.025 & -0.028 & -0.002 \\
\hline 2002 & 0.025 & 0.007 & 3.410 & 0.001 & 0.010 & 0.039 & |-0.015 & 0.006 & -2.512 & 0.012 & -0.027 & -0.003 & -0.027 & 0.007 & -4.031 & 0.000 & -0.040 & -0.014 \\
\hline 2003 & 0.010 & 0.007 & 1.355 & 0.175 & -0.005 & 0.025 & 0.004 & 0.006 & 0.737 & 0.461 & -0.007 & 0.015 & -0.019 & 0.007 & -2.929 & 0.003 & -0.032 & -0.006 \\
\hline 2005 & 0.011 & 0.007 & 1.454 & 0.146 & -0.004 & 0.025 & $\mid-0.007$ & 0.006 & -1.186 & 0.236 & -0.018 & 0.004 & -0.022 & 0.007 & -3.322 & 0.001 & -0.035 & -0.009 \\
\hline 2006 & 0.029 & 0.007 & 4.058 & 0.000 & 0.015 & 0.042 & $\mid-0.013$ & 0.006 & -2.302 & 0.021 & -0.024 & -0.002 & -0.023 & 0.006 & -3.520 & 0.000 & -0.035 & -0.010 \\
\hline 2007 & 0.015 & 0.007 & 2.142 & 0.032 & 0.001 & 0.029 & 0.004 & 0.005 & 0.866 & 0.386 & -0.006 & 0.015 & -0.026 & 0.007 & -3.959 & 0.000 & -0.039 & -0.013 \\
\hline 2008 & 0.026 & 0.007 & 3.747 & 0.000 & 0.012 & 0.040 & $\mid-0.007$ & 0.006 & -1.272 & 0.203 & -0.018 & 0.004 & -0.029 & 0.007 & -4.429 & 0.000 & -0.042 & -0.016 \\
\hline 2009 & 0.013 & 0.007 & 1.857 & 0.063 & -0.001 & 0.026 & 0.003 & 0.005 & 0.602 & 0.547 & -0.007 & 0.014 & -0.021 & 0.006 & -3.285 & 0.001 & -0.033 & -0.008 \\
\hline 2010 & 0.030 & 0.007 & 4.418 & 0.000 & 0.016 & 0.043 & $\mid-0.007$ & 0.005 & -1.273 & 0.203 & -0.017 & 0.004 & -0.047 & 0.006 & -7.363 & 0.000 & -0.059 & -0.034 \\
\hline 2011 & 0.011 & 0.007 & 1.582 & 0.114 & -0.003 & 0.024 & 0.009 & 0.005 & 1.779 & 0.075 & -0.001 & 0.020 & -0.030 & 0.006 & -4.693 & 0.000 & -0.042 & -0.017 \\
\hline 2012 & 0.027 & 0.007 & 4.117 & 0.000 & 0.014 & 0.040 & 0.002 & 0.005 & 0.317 & 0.751 & -0.009 & 0.012 & -0.032 & 0.006 & -4.981 & 0.000 & -0.044 & -0.019 \\
\hline 2013 & 0.025 & 0.010 & 2.525 & 0.012 & 0.006 & 0.045 & \begin{tabular}{|l|l|} 
& 0.027
\end{tabular} & 0.009 & 3.072 & 0.002 & 0.010 & 0.044 & -0.035 & 0.009 & -3.706 & 0.000 & -0.053 & -0.016 \\
\hline 2014 & 0.029 & 0.007 & 4.234 & 0.000 & 0.015 & 0.042 & 0.014 & 0.006 & 2.433 & 0.015 & 0.003 & 0.026 & \begin{tabular}{|l}
-0.030 \\
-0.044
\end{tabular} & 0.007 & -6.630 & 0.000 & -0.057 & $\begin{array}{l}-0.031 \\
-0.031\end{array}$ \\
\hline 2015 & 0.041 & 0.006 & 6.417 & 0.000 & 0.029 & 0.054 & 0.009 & 0.006 & 1.671 & 0.095 & -0.002 & 0.021 & -0.045 & 0.006 & -6.968 & 0.000 & -0.058 & -0.032 \\
\hline 2016 & 0.037 & 0.006 & 5.816 & 0.000 & 0.025 & 0.050 & 0.017 & 0.006 & 2.869 & 0.004 & 0.005 & 0.029 & -0.048 & 0.007 & -7.272 & 0.000 & -0.061 & -0.035 \\
\hline
\end{tabular}

Table A9. Average partial effect (and 95\% confidence intervals) from fractional logit models measuring average difference between individuals with medium-lower education and tertiary educated in the probability of adopting different dietary styles. Source: ISTAT-MDS 1997-2016. 


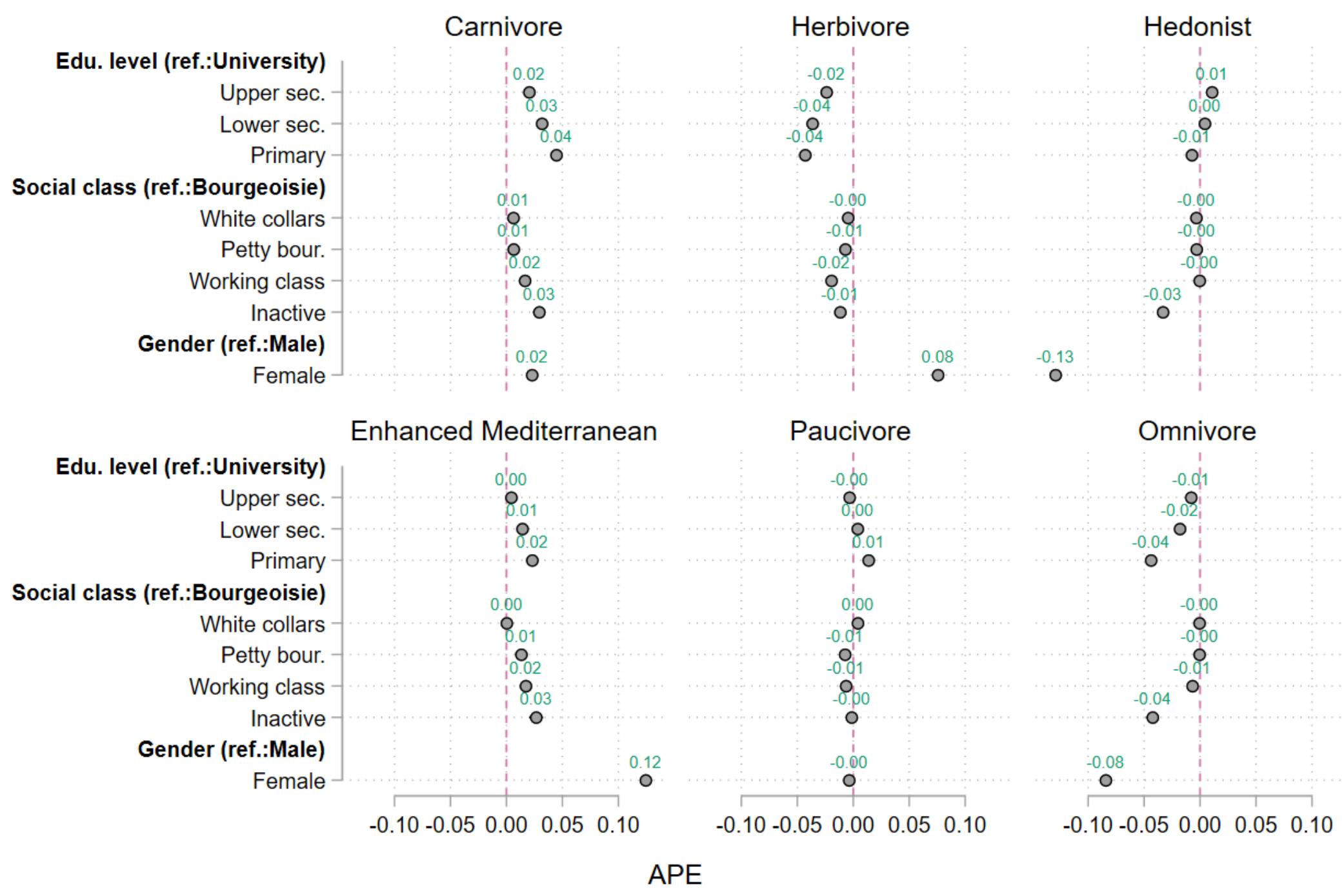

Figure A1. Fractional logit models: average partial effects of education, social class, and gender on the probability of adopting different dietary styles. Years 2001-2016. Pooled sample (N=335,842). Source: ISTAT-MDS 1997-2016. 


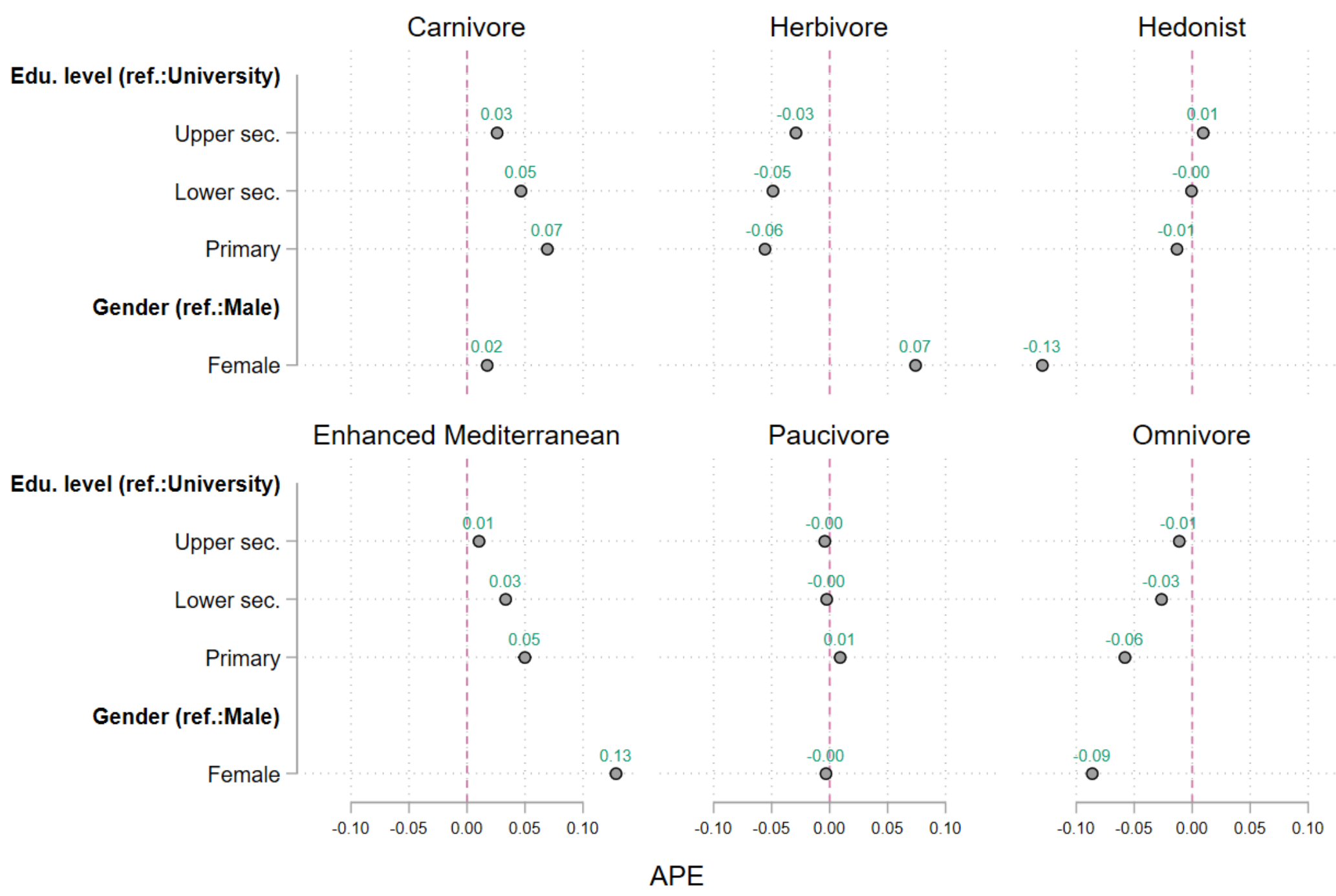

Figure A2. Multinomial logit models: average partial effects of education and gender on the probability of adopting different dietary styles. Pooled sample $(\mathrm{N}=481,359)$. Source: ISTAT-MDS 1997-2016. 
Figure A3. Average number of meat-based dishes per week by gender. Pooled sample $(\mathrm{N}=481,359)$. Source: ISTAT-MDS 1997-2016.

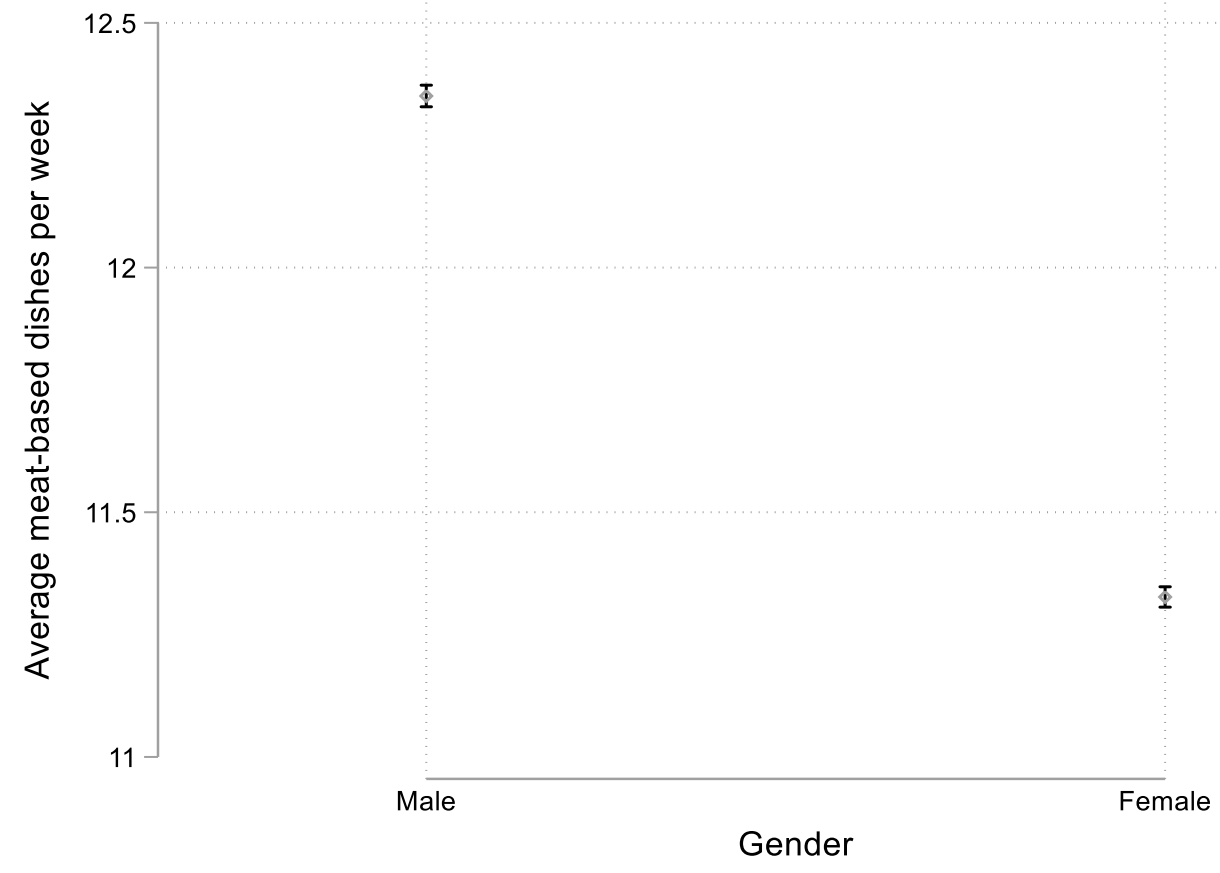

$95 \%$ confidence intervals 
Figure A4. Average number of wine/beer glasses per week by education level. Pooled sample $(\mathrm{N}=481,359)$. Source: ISTAT-MDS 1997-2016.

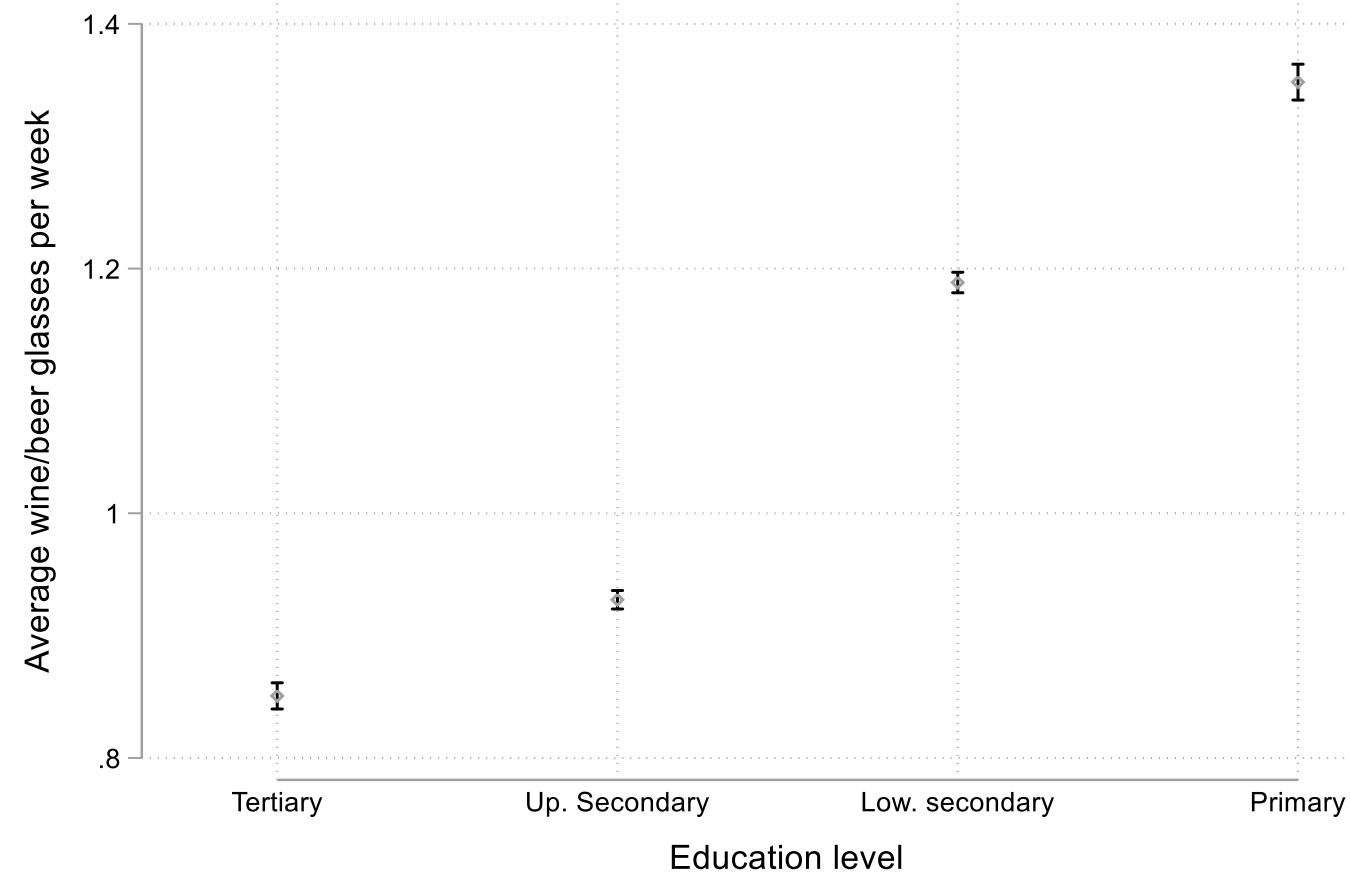

$95 \%$ confidence intervals 


\section{References}

Abel, T. (2008). Cultural capital and social inequality in health. Journal of Epidemiology \& Community Health, 62(7), e13.

Alderson A, Junisbai A \& Heacock I. (2007) Social status and cultural consumption in the United States, Poetics, 35, 191-212

Bourdieu P. 1984 [1979]. Distinction: A Social Critique of the Judgement of Taste. London: Routledge

Bourdieu, P. (2011). The forms of capital. In I. Szeman \& T. Kaposy (Eds.), Cultural theory: An anthology (pp. 81-93). Chichester: Wiley-Blackwell.

Bryson, B. (1996). " Anything but heavy metal": Symbolic exclusion and musical dislikes. American sociological review, 884-899.

Buis M.L. (forthcoming). Analysis of proportions, SAGE Research Methods Foundations: An Encyclopedia, available at http://www.maartenbuis.nl/publications/prop.html (Last access 26 July 2019).

Caritas (2015). $15^{\circ}$ Rapporto Immigrazione 2015. La cultura dell'incontro. Todi: Tau Editrice.

Chan T. W. \& Goldthorpe J. H. (2007a) Social stratification and cultural consumption: music in England, European Sociological Review, 23, 1-19

Chan T. W. \& Goldthorpe J. H. (2007b) Social stratification and cultural consumption: the visual arts in England, Poetics, 35, 168-190

Cheng, S. L., Olsen, W., Southerton, D., \& Warde, A. (2007). The changing practice of eating: evidence from UK time diaries, 1975 and 2000 1. The British journal of sociology, 58(1), 39-61.

Cleveland, W. S. (1979). Robust locally weighted regression and smoothing scatterplots. Journal of the American Statistical Association 74: 829-836.

Coulangeon, P., \& Lemel, Y. (2007). Is 'distinction'really outdated? Questioning the meaning of the omnivorization of musical taste in contemporary France. Poetics, 35(2-3), 93-111.

Connell, R.W. (1995). Masculinities. Cambridge: Polity.

Courtenay, W. H. (2000). Constructions of masculinity and their influence on men's well-being: a theory of gender and health. Social science \& medicine, 50(10), 1385-1401.

Currid-Halkett, E. (2017). The sum of small things: A theory of the aspirational class. Princeton: Princeton University Press.

Darmon, N., \& Drewnowski, A. (2008). Does social class predict diet quality? The American journal of clinical nutrition, 87(5), 1107-1117.

DeSoucey, M. (2010). Gastronationalism: Food traditions and authenticity politics in the European Union. American Sociological Review, 75(3), 432-455.

Dickie, J. (2008). Delizia! The epic history of the Italians and their food. London: Hodder \& Stoughton. 
Drewnowski, A., \& Eichelsdoerfer, P. (2009). The Mediterranean diet: Does it have to cost more? Public Health Nutrition, 12(9A), 1621-1628.

Elias, N. (2000) The civilizing process. Sociogenetic and psychogenetic investigations. Oxford: Blackwell Publishing.

Esping-Andersen, G. (2009) The Incomplete Revolution: Adapting to Women's New Roles. Cambridge: Polity Press.

Eurispes (2019). $31^{\circ}$ Rapporto Italia 2019. Istituto di Studi Politici Economici e Sociali. Available at: https://bit.ly/2wadnUQ Last access 26 May 2019

Ferro-Luzzi, A., \& Branca, F. (1995). Mediterranean diet, Italian-style: prototype of a healthy diet. The American journal of clinical nutrition, 61(6), 1338S-1345S.

Fishman, R. M., \& Lizardo, O. (2013). How macro-historical change shapes cultural taste: legacies of democratization in Spain and Portugal. American Sociological Review, 78(2), 213-239.

Flemmen, M., Hjellbrekke, J., \& Jarness, V. (2018). Class, culture and culinary tastes: Cultural distinctions and social class divisions in contemporary Norway. Sociology, 52(1), 128-149.

Garcia-Alvarez E, Katz-Gerro T \& López-Sintas J. (2007) Deconstructing cultural \& omnivorousness 1982-2002: Heterology in Americans' musical preferences, Social Forces, 86, 417-443

Gronow, J., \& Holm, L. (Eds.). (2019). Everyday Eating in Denmark, Finland, Norway and Sweden: A Comparative Study of Meal Patterns 1997-2012. London: Bloomsbury Academic.

Heisig, J. P., Schaeffer, M., \& Giesecke, J. (2017). The costs of simplicity: Why multilevel models may benefit from accounting for cross-cluster differences in the effects of controls. American Sociological Review, 82(4), 796-827.

Huddart Kennedy, E., Baumann, S., \& Johnston, J. (2018). Eating for Taste and Eating for Change: Ethical Consumption as a High-Status Practice. Social Forces, online first.

Lelieveldt, H. (2017). Comment on DeSoucey: Gastronationalism or Gastroregionalism? Available at SSRN: https://ssrn.com/abstract=2984754. (Last access 26 July 2019).

Lindblom, T., \& Mustonen, P. (2019). 'Anything but heavy meal'-Culinary dislikes and patterned intolerance among the young urban Finns. Social Science Information, 58(1), 193-218.

Johnston, J., \& Baumann, S. (2014). Foodies: Democracy and distinction in the gourmet foodscape. New York: Routledge.

Kanerva M (2013) Meat consumption in Europe: Issues, trends and debates, Artec-paper Nr. 187, January 2013, Universitat Bremen, Bremen, ISSN1613-4907, www.academia.edu/2486553/ (Last access 26 July 2019.

Kaplan, D. (2013). Food and class distinction at Israeli weddings: New middle class omnivores and the "simple taste". Food, Culture \& Society, 16(2), 245-264. 
Katz-Gerro, T., \& Jæger, M. M. (2013). Top of the pops, ascend of the omnivores, defeat of the couch potatoes: Cultural consumption profiles in Denmark 1975-2004. European Sociological Review, 29(2), 243-260.

Leitch, A. (2003). Slow food and the politics of pork fat: Italian food and European identity. Ethnos, 68(4), 437-462.

Lomazzi, V. (2017). Gender role attitudes in Italy: 1988-2008. A path-dependency story of traditionalism. European Societies, 19(4), 370-395.

López-Sintas J \& Katz-Gerro T. (2005) From exclusive to inclusive elitists and further: twenty years of omnivorousness and cultural diversity in arts participation in the USA, Poetics, 33, 299-319

Mandemakers, J. J., \& Roeters, A. (2015). Fast or slow food? Explaining trends in food-related time in the Netherlands, 1975-2005. Acta Sociologica, 58(2), 121-137.

Magidson, J., \& Vermunt, J. K. (2004). Latent class models. In Kaplan, D. (ed.) The Sage handbook of quantitative methodology for the social sciences, (pp. 175-198). London: Sage.

McCutcheon, A. L. (1987). Latent class analysis (No. 64). London: Sage.

Martin, K. S., Rogers, B. L., Cook, J. T., \& Joseph, H. M. (2004). Social capital is associated with decreased risk of hunger. Social Science \& Medicine, 58(12), 2645-2654.

Mennell, S. (1985). All manners of food: eating and taste in England and France from the Middle Ages to the present. Oxford: Blackwell.

Mestdag, I., \& Glorieux, I. (2009). Change and stability in commensality patterns: a comparative analysis of Belgian time-use data from 1966, 1999 and 2004. The Sociological Review, 57(4), 703726.

de Morais Sato, P., Lourenço, B. H., Trude, A. C. B., Unsain, R. F., Pereira, P. R., Martins, P. A., \& Scagliusi, F. B. (2016). Family meals and eating practices among mothers in Santos, Brazil: A population-based study. Appetite, 103, 38-44.

Oehlert, G. W. (1992). A note on the delta method. American Statistician 46: 27-29.

Oleschuk, M., Johnston, J., \& Baumann, S. (2019). Maintaining Meat: Cultural Repertoires and the Meat Paradox in a Diverse Sociocultural Context. Sociological Forum, online first.

Oncini, F. (2019). Feeding distinction: Economic and cultural capital in the making of food boundaries. Poetics, 73, 17-31.

Oncini, F., \& Guetto, R. (2017). Determinants of dietary compliance among Italian children: disentangling the effect of social origins using Bourdieu's cultural capital theory. Sociology of health \& illness, 39(1), 47-62.

Oncini, F., \& Guetto, R. (2018). Cultural capital and gender differences in health behaviours: A study on eating, smoking and drinking patterns. Health Sociology Review, 27(1), 15-30.

Paddock, J. (2015). Invoking simplicity: 'Alternative' food and the reinvention of distinction. Sociologia Ruralis, 55(1), 22-40. 
Paddock, J. (2016). Positioning food cultures: 'Alternative' food as distinctive consumer practice. Sociology, 50(6), 1039-1055.

Papke, L. E., \& Wooldridge, J. M. (1996). Econometric methods for fractional response variables with an application to 401 (K) plan participation rates. Journal of Applied Econometrics, 11(6), 619632.

Pedersen, W., Jarness, V., \& Flemmen, M. (2018). Revenge of the nerds: Cultural capital and the politics of lifestyle among adolescent elites. Poetics, online first.

Peterson, R. A. (1992). Understanding audience segmentation: From elite and mass to omnivore and univore. Poetics, 21(4), 243-258.

Pietro, G. D. (2016). The Impact of Television Programmes on Teenage Career Aspirations: The 'MasterChef Effect'. IZA Discussion Papers, N. 9804, Institute for the Study of Labor (IZA), Bon.

Plessz, M., \& Étilé, F. (2019). Is cooking still a part of our eating practices? Analysing the decline of a practice with time-use surveys. Cultural Sociology, 13(1), 93-118.

Plessz, M., \& Gojard, S. (2015). Fresh is best? Social position, cooking, and vegetable consumption in France. Sociology, 49(1), 172-190.

Purhonen, S., \& Gronow, J. (2014). Polarizing appetites? Stability and change in culinary tastes in Finland, 1995-2007. Food, Culture \& Society, 17(1), 27-47.

Rothgerber, H. (2013). Real men don't eat (vegetable) quiche: Masculinity and the justification of meat consumption. Psychology of Men \& Masculinity, 14(4), 363.

Sobal, J. (2005). Men, meat, and marriage: Models of masculinity. Food and Foodways, 13(1-2), 135-158.

Skafida, V. (2013). The family meal panacea: exploring how different aspects of family meal occurrence, meal habits and meal enjoyment relate to young children's diets. Sociology of health \& illness, 35(6), 906-923.

Strutz, T. (2016). Data Fitting and Uncertainty: A Practical Introduction to Weighted Least Squares and Beyond. Wiesbaden: Vieweg Springer.

Van Gundy, K., Schieman, S., Kelley, M.S., \& Rebellon, C.J. (2004). Gender role orientations and alcohol use among Moscow and Toronto adults. Social Science \& Medicine, 61(11), 2317-2330.

Vermunt, J. K., \& Magidson, J. (2004). Latent class analysis. In Lewis-Beck, M., Bryman, A. and Liao, T. F. Eds.) The sage encyclopedia of social sciences research methods, (pp. 549-553) Newbury Park: Sage.

Warde, A. (2011). Cultural hostility re-considered. Cultural Sociology, 5(3), 341-366.

Warde, A. (2015). The sociology of consumption: Its recent development. Annual Review of Sociology, 41, 117-134.

Warde, A., Whillans, J., \& Paddock, J. (2019). The allure of variety: Eating out in three English cities, 2015. Poetics, 72, 17-31. 
Warde, A., Wright, D., \& Gayo-Cal, M. (2007). Understanding cultural omnivorousness: Or, the myth of the cultural omnivore. Cultural sociology, 1(2), 143-164.

Wardle, J., Haase, A. M., Steptoe, A., Nillapun, M., Jonwutiwes, K., \& Bellisie, F. (2004). Gender differences in food choice: the contribution of health beliefs and dieting. Annals of behavioral medicine, 27(2), 107-116.

Willett, W., Rockström, J., Loken, B., Springmann, M., Lang, T., Vermeulen, S., ... \& Jonell, M. (2019). Food in the Anthropocene: the EAT-Lancet Commission on healthy diets from sustainable food systems. The Lancet, 393(10170), 447-492.

Wooldridge, J. M. 2010. Econometric Analysis of Cross Section and Panel Data. Cambridge: Massachusetts Institute of Technology Press.

Yates, L., \& Warde, A. (2015). The evolving content of meals in Great Britain. Results of a survey in 2012 in comparison with the 1950s. Appetite, 84, 299-308.

Zavisca J. (2005) Status of cultural omnivorism: a case study of reading in Russia, Social Forces, 84, 1233-1255 